\title{
برنامج مقترح لتدريس آلة الكمان عن بعد للطالب المتخصص من خلال برنامج زوم Zoom
}

د. علاء فكري منصور*

مقدمة

مرت آلة الكمان بتطورات عديدة منذ نشأتها من حيث حجمها وصناعتها وتثنيات العزف عليها

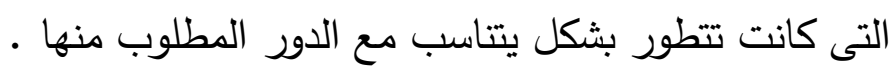
وقد تعددت مدارس العزف على آلة الكمان وتتوعت أشكال تتاولها للتقنيات العزفية المختلفة ، حيث ليثل وصلت هذه المدارس العالمية إلى مستوى عالِ من التقدم والتطور , فوضعت أسس تعليم الآلّة والمناهج العلمية المبنية على القواعد التى تعطى التوازن بين تقنيات اليد اليمنى (القوس) , واليد اليسرى.

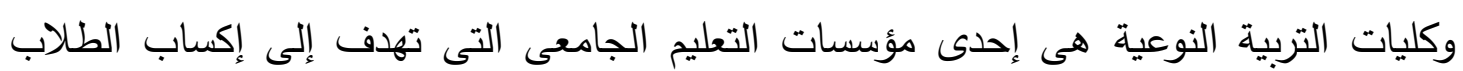

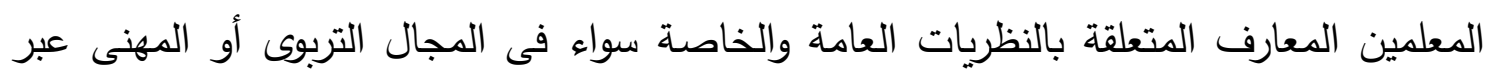
مجال التخصص الأكاديمى.

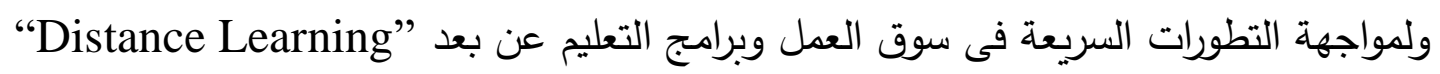

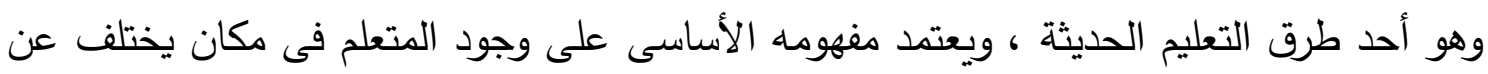

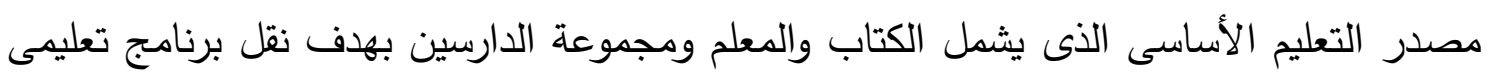

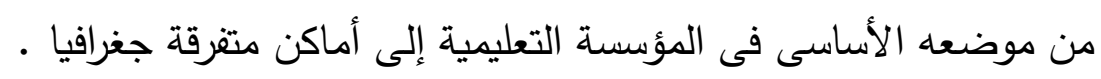

\section{مشكلة البحث}

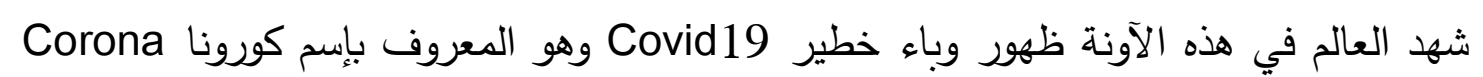
والذى راح ضحيته مئات الألوف حول العالم إلى جانب ملايين الدصابين والذى مازالت فئت أثارة مستمراً

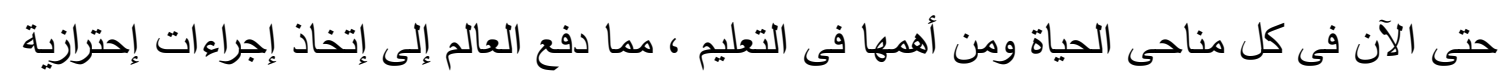
مشددة بغرض الحد من إنتشار هذا الوباء وكان من أهمها التباعد الجسدى الهئ.

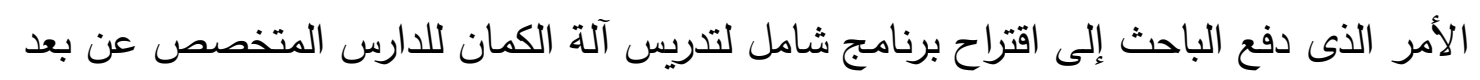

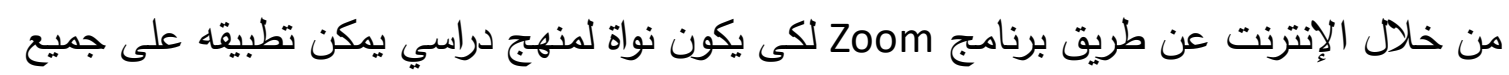

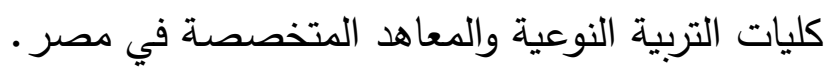


يهدف هذا البحث إلى تصميم برنامج مقترح لدراسة آلة الكمان عبر الأنترنت باستخدام برنامج

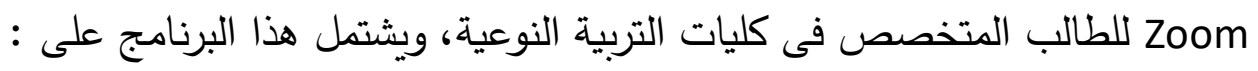

( ) (بقنيات الأداء لحركة القوس باليد اليمنى صعوداً وهبوطاً.

r) السلالم المناسبة للمرحلة الدراسية.

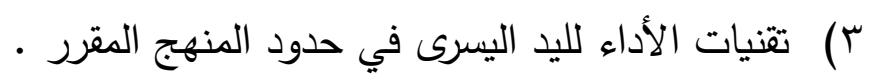

أهمية البحث

تدريس آله الكمان من خلال برنامج Zoom يساهم فى رفع مستوى الآداء على آلة الكمان ،

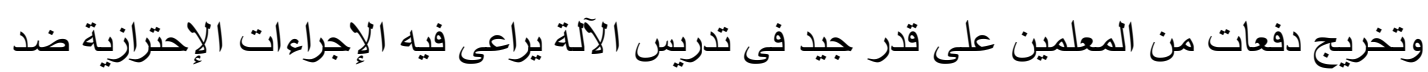
وباء الكورونا أو أى أوبئة أخرى لا قدر الله.

أسئلة البحث : البوروناء

من خلال الدروس التجريبية التى وضعها الباحث لتدريس الآلة عن بعد من خلال برنامج Zoom

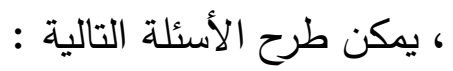

(1) ما مدى تمكن الدارس من اداء تقنيات حركة القوس لليد اليمني صعوداً وهبوطاً بطريقة علمية صحيحة؟

r r ماهي انسب الطرق لتذليل صعوبات المنهج لطالب كلية التربية النوعية ؟ r) ما مدى تمكن الدارس من اداء (تقنيات اليد اليمنى (القوس) - تقنيات اليد اليسرى) ؟

حدود البحث:

- الحدود المكانية : كليه التربية النوعية جامعه القاهرة . - الحدود الزمنيه : تطبيق البرنامج خلال الترم الثاني من العام الدراسي. منهج البحث :

يتبع هذا البحث المنهج التجريبى (منهج المجموعة الواحدة)

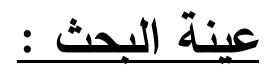

طلاب الفرقة الأولي من دارسي آلة الكمان المتخصصين بقسم التربية الموسيقية بكلية التربية النوعية

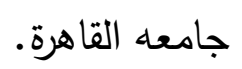

مجلة علوم وفنون الموسيقى - كلية التربية الموسيقية - المجلد الخامس والأربعون - يوليو الr.rم 


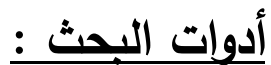

( ) استمارة استطلاع رأى الخبراء فى مدى مناسبة المنهج المقترح ·

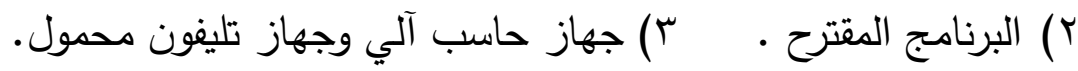

مصطلحات البحث:

Distance Learning التعليم عن بعد مهند هو أي عملية تعليمية لا يحدث فيها اتصال مباشر بين الطالب والمعلم، بحيث يكونان متباعدين

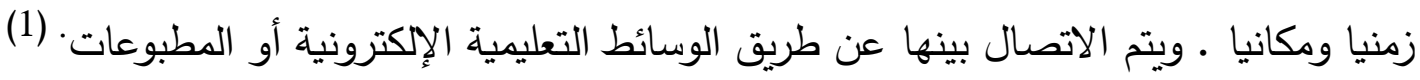
وبطريقة أخرى: - | - |

يعرف بأنه التعليم الذاتي أو الدراسة المستقلة والذي يتم في مكان غير وجود المعلم. ويسمى أحياناً بالتعليم بالمراسلة وأحياناً أخرى بالتعلم الإلكتروني.

Program : برنامج

" هو المخطط العام الذي وضـع في وقت سـابق ويتضـمن مجموعة من المواد التعليمية التي قد تكون كفايات تدريسـية تحدد للطلاب، ويحدد لله فترة زمنية، وقد يدرس المتعلم البرنامج داخل

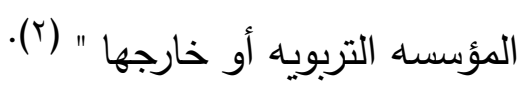

Techniques : تقنيات

" تعريب لكلمة (تكنيك) وهي عبارة عن تمرينات رياضــية للأصــابع يؤديها الدارس على الآلة

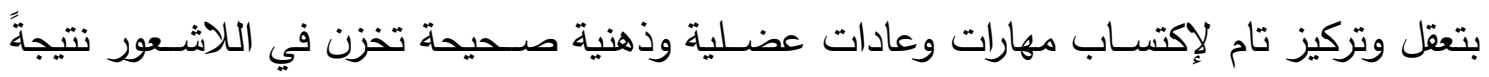
للتمرين اليومي حتى تصبح تلقائية أو أوتوماتيكية " (־).

(1) Jodi L , Longitudinal Analysis of Student Performance in a Dental Hygiene Distance Education Program , Journal of Dental Education Volume 66, No. 9 , 2002

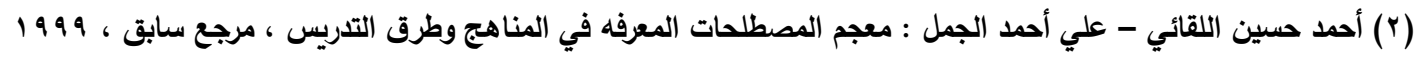

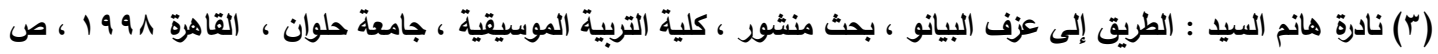


Violin : آلة الكمان " هي الآلة الأساسية الحديثة في مجموعة الآلات الوترية ذات القوس، تُعزف محمولة على الذراع

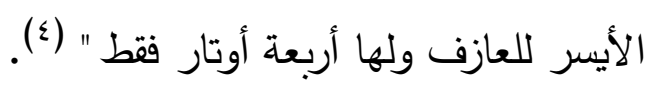

\section{Specialized student : الطالب المتخصص}

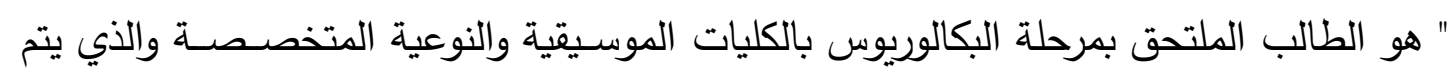

$$
\begin{aligned}
& \text { تخصصه آله اولي كمان " (r) } \\
& \text { وينقسم البحث الى جزئين:- } \\
& \text { اولاً:الاطار النظرى ويشمل : } \\
& \text { - - دراسات سابقة } \\
& \text { - - - إستخدامات الحاسب الآلي } \\
& \text { - - - تقنيات العزف على آلة الكمان }
\end{aligned}
$$

بعنوان(") " فاعلية برنامج مقترح لتحسين الآداءات المهنية للطالب معلم التربية

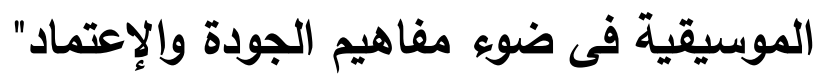

يهدف هذا البحث إلى إعداد معايير الجودة الثاملة للآداء المهنى لدى الطالب (معلم التربية

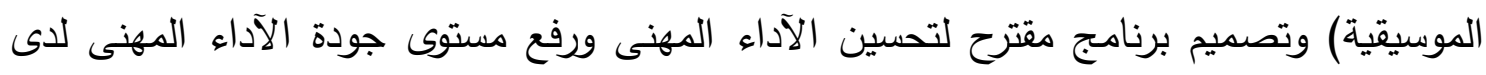
الطالب (معلم التربية الموسيقية) الذى يقوم على معايير الجودة الثاملة وقياس فاعليته فى تحسين الآداء المهنى ووعيه بمعايير جودتها لإعتماده كمعلم للتربية الموسيقية ، كما يهدف إلى زيلى زيادة الكفاءة التدريسية لديه فى مادة التربية الموسيقية من خلال بنود الصولفيج والإيقاع الحركى والإرتجال

( ) معجم الموسيقى : مركز الحاسب الآلي ، مجمع اللغة العربية ، الهيئة العامة لشئون المطابع الأميرية ، القاهرة ... r ، ص

$$
\text { (3) تعريف إجرائي للبحث }
$$

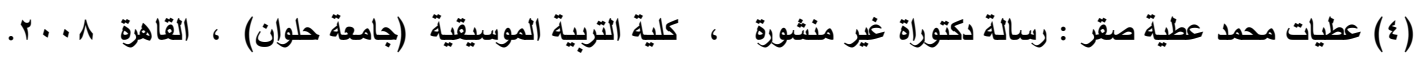

مجلة علوم وفنون الموسيقى - كلية التربية الموسيقية - المجلد الخامس والأربعون - يوليو الr.rم 
الموسيقى وطرق التدريس وإمداده بالخبرات الجديدة والمهارات التخصصية حتى يكون خريج مواكب

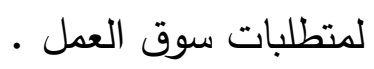

اتفقت تلك الدراسة مع البحث الحالي في الاهتمام بتقديم انسب واكفأ الطرق لدراسة الة الكمان

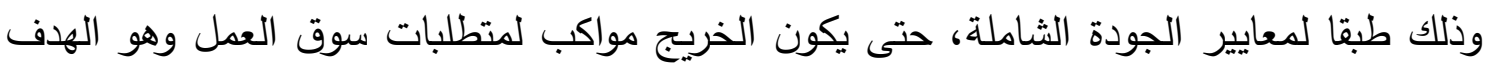
المنشود. - (الم.

\section{الاراسة الثانية:}

بعنوان"تقنيات كارل فليش لآلة الكمان وإمكانية الإستفادة منها لطالب كلية التربية الموسيقية" " - تهدف تلك الدراسة إلى : ( ) التعرف على بعض تقتيات كارل فليش وأسلوبه في التدريس. r) الإستفادة من بعض تقنيات كارل فليش في تدريس آلة الكمان والتي تسهم في إثراء وتحسين أداء الطلاب في فترة زمنية مختصرة.

- اتبعت تلك الدراسة المنهج الوصفي التحليلي (تحليل محتوى). - تكونت عينة تلك الدراسة من بعض التقنيات الفنية المنتقاه والمحددة لآلة الكمان لكارل فليش. - توصلت تلك الدراسة إلى : ( ) التعرف على خصائص إسلوب كارل فليش في دراسة الكمان يثري الجوانب المختلفة للأداء.

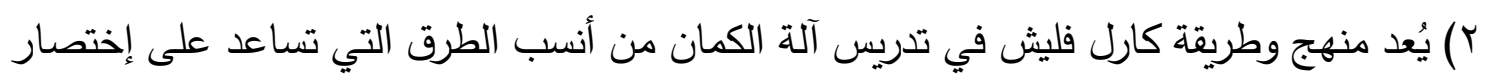
الفترة الزمنية التي تعمل على تحسين العزف على على آلة الكمان. - استفاد الباحث من تلك الدراسة في الإهتمام بالتقنيات العزفية لآلة الكمان لتحسين أداء الطالب البعان

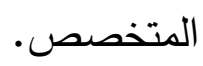
اتققت تلك الدراسة مع البحث الحالي في اهتمامها بتنمية مهارات الأداء لدى دارسي آلة الكمان.

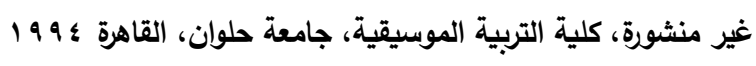




\section{"Music Education in Japan" : (') بعنوان}

\section{"التعليم الموسيقى فى اليابان"}

يهدف هذا البحث إلى إظهار الوضع القائم لأسلوب إعداد مدرسى الأطفال فى اليابان ، وقد تتاولت الته

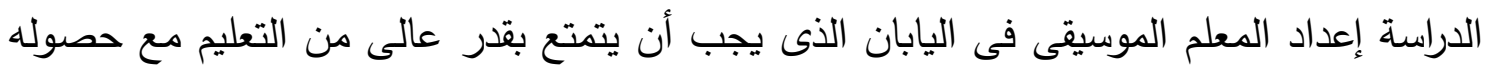

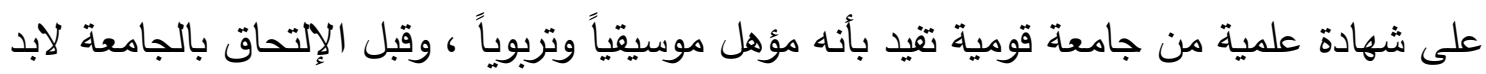

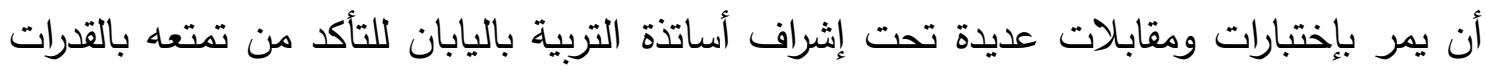

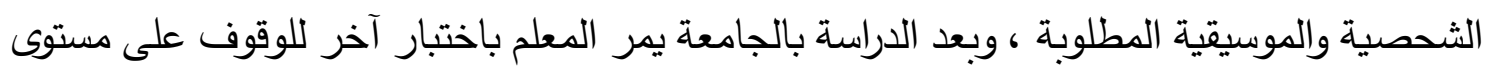

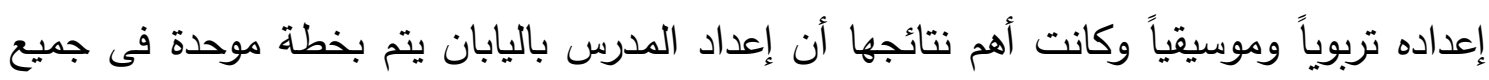

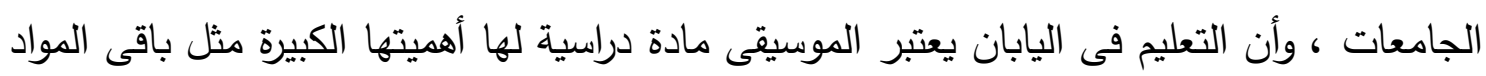

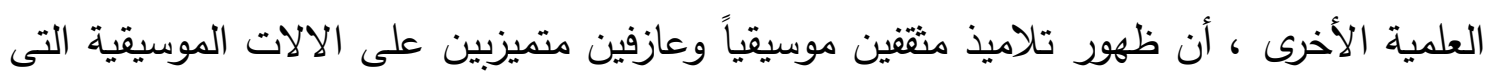
يختارونها ماهو إلا نتاج لإهتمام الدولة الكبير بالموسيقى بشتى فلى فروعها.

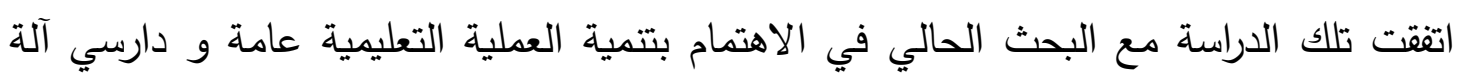

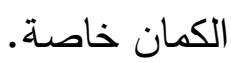

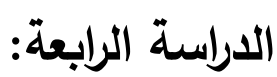

"A naturalistic study of the organized student teaching (r) بعنوان experience of students in an early childhood preparation program" "دراسة تجربة التعليم المنظم للطالب المعلم أثناء برنامج إعداد معلم مرحلة الطفولة

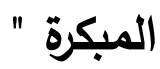
يهرف هذا البحث إلى مناقثة تجربة التعليم المنظم للطلاب الذين يتم إعدادهم ليصبحوا معلمين

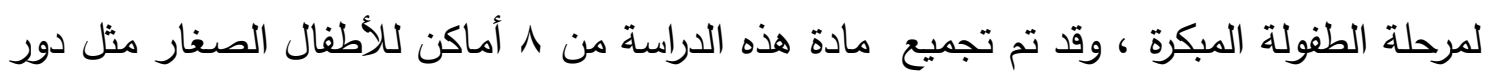

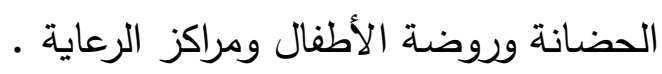

وقد إتبع هذه البحث المنهج الوصفى من خلال فصل دراسى مدته الأه الرعاية ، 17 أسبوعاً ، ويتضمن هذا البحث ملاحظات المشاركين فى تسجيل رسمى وغير رسمى للمشاركة ومقابلات مدونة ، وقد تم

(1)Tsuneaki Migoshi : Design, typewriting and printing by the printer, University of Centerburg, 1992.

(2) Silver Miriam : edd, New Lark University, 1982.

مجلة علوم وفنون الموسيقى - كلية التربية الموسيقية - المجلد الخامس والأربعون - يوليو ابr.rم 
إستخدام الإطار الذى وصف لتنظيم الدراسة ونتائج مشاركة كل طالب فى ثلاث نقاط هى :وضوح

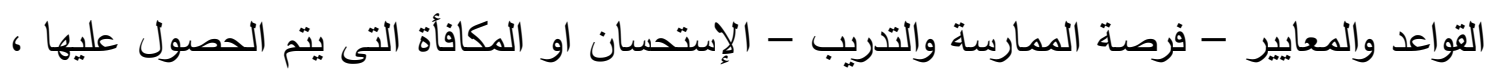

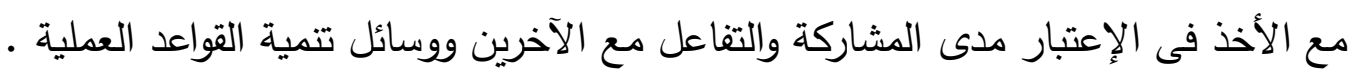

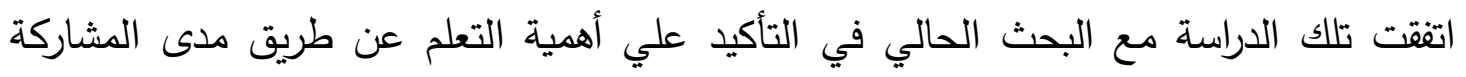

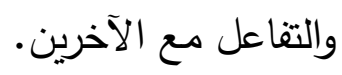

$$
\text { إستخدامات الحاسب الآلي : - (1) }
$$

تطورت أساليب إستخدام الحاسب الألي في التعليم , وأضبح الاهتمام الأن منصبا علي تطوير

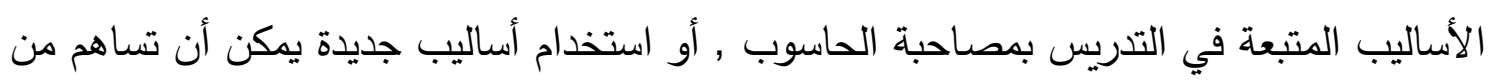
خلالها في تحقيق بعض أهداف المواد الدراسية. وهناك مجموعة من المجالات المتنوعة التي يمكن أن يستخدم فيها الحاسب الألي في العملية التعليمية: 1

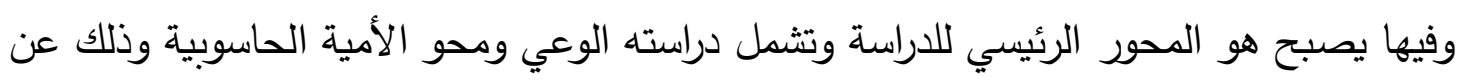

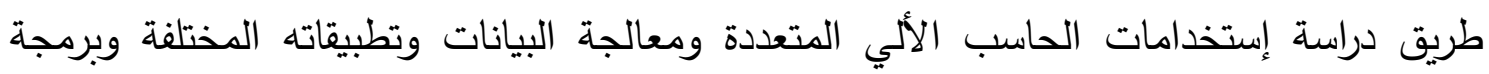
الحاسب الألي ونظام التشغيل . : ب - كوسيلة تعليمية يعد الحاسب الألي وسيلة متطورة لنقل العديد من المواد الدراسية وتوزيعها لما له من خصائصها

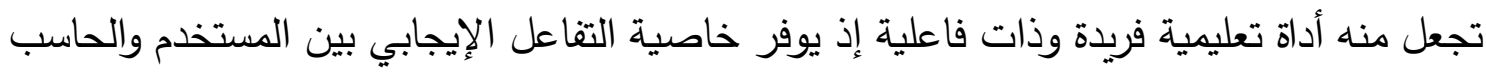
الألي , كما يوفر العناية الخاصة , ويعد وسيلة تحفيز هائلة ويعمل علي تتمية العديد من الإتجاهات

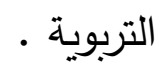

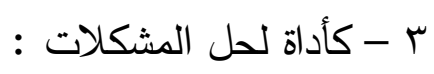
إن إستخدام الحاسب الألي لحل مشكلة تتضمن بعض المتغيرات يسمح بتحويل مركز الإهتمام من

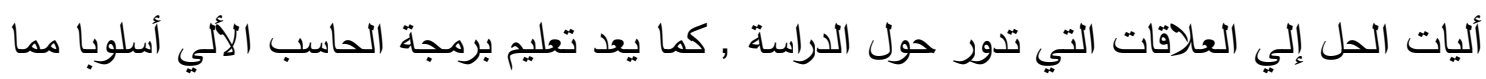
يتيح للطلاب فرصة تنمية مهارة حل المشكلات .

(ץ) أسامة محمد سمير : استخدامات الحاسب الآلي في برمجة الثبكات العنكبوتية ، رسالة دكتوراة ، كلية الهنسة ، جامعة القاهرة

مجلة علوم وفنون الموسيقى - كلية التربية الموسيقية - المجلد الخامس والأربعوذ - يوليو ابrrم 
ع - كأداة لتقديم المواد الدراسية :

يعد الحاسب الألي أداة فعالة بين يدي المعلم الواعي والطموح إذ يستطيع أن يستثره في تقديم

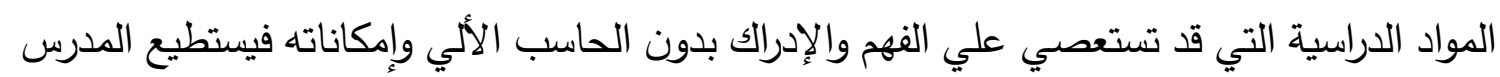

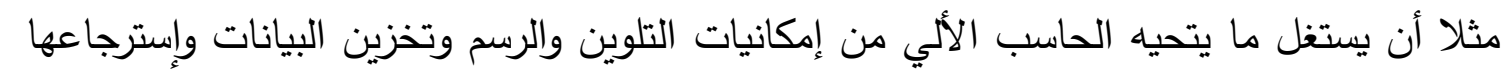

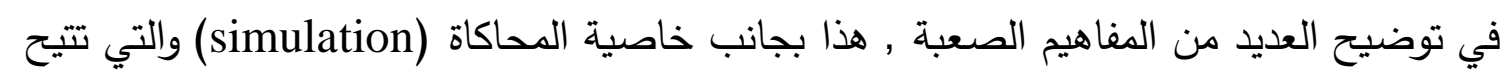

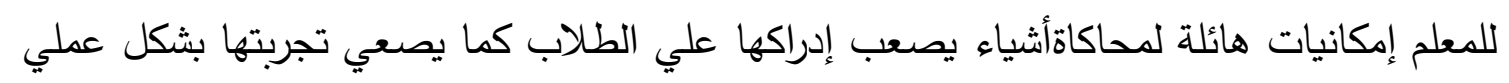

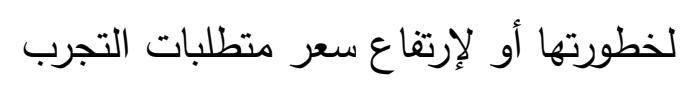
مميزات إستخدام الحاسب الآلي في التعليم :

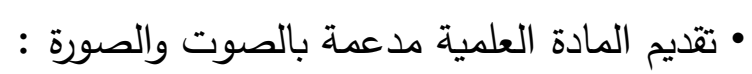
يساعد الحاسب الألي المعلم بثكل كبير علي تقديم صور توضيحية مفصلة لموضوع الدرس وأيضا

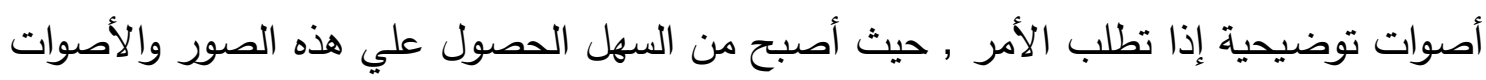

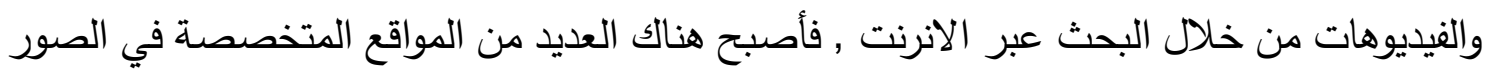

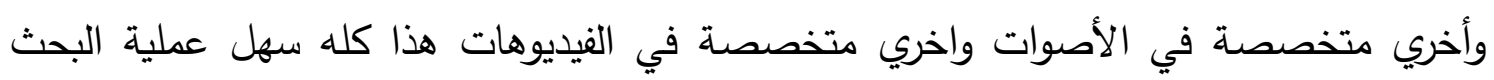

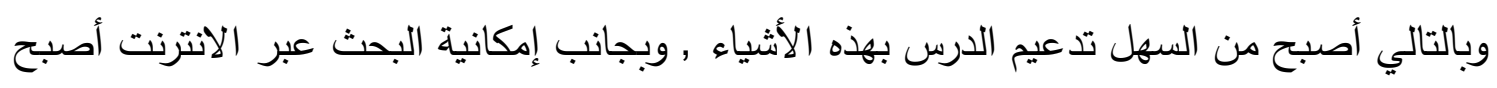

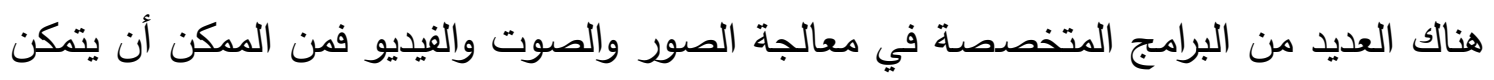

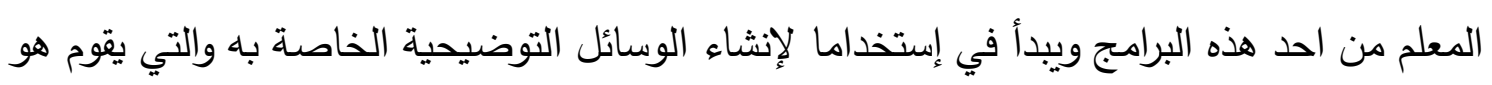
بنفسه بتثكيلها وتهيئتها تبعا للهدف المطلوب تحقيقه من الدرس وتبعا للمعلومات الدئل المراد إكسابها للمتعلم . للعهل

• • إمكانية إعادة المعلومات مرات عديدة بكل يسر وسهولة : من أهم الميزات التي يقدمها الحاسب الآلي عند إستخدامها هي التعليم هو أنه يعطي للمتعلم

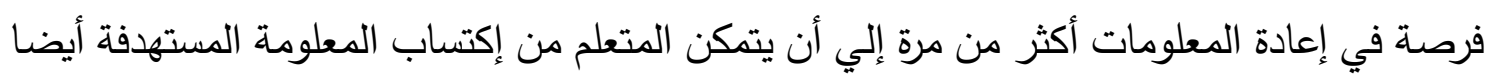

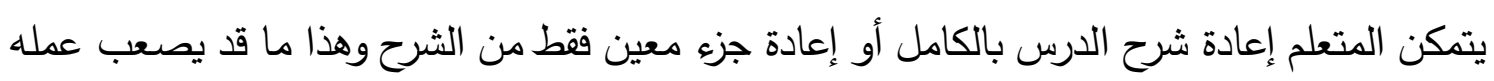

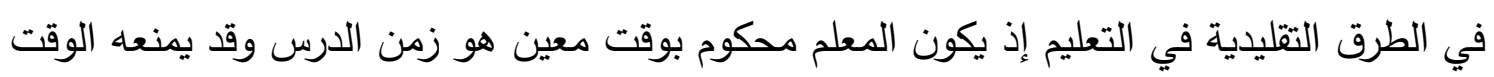

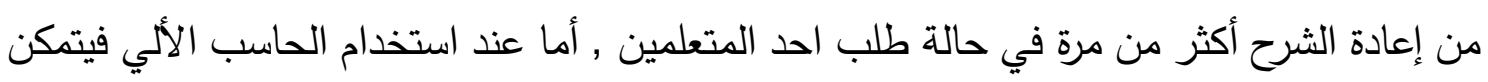

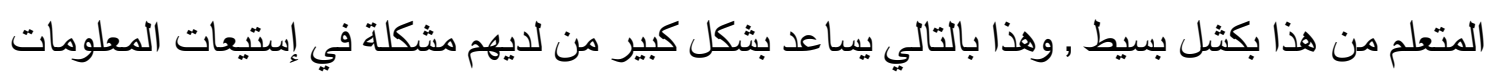

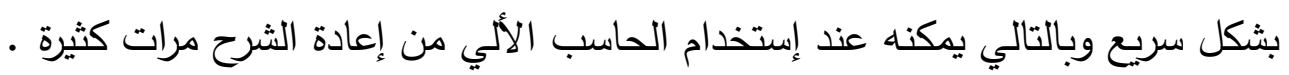




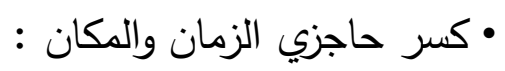

عند استخدام الحاسب الألي ومع توافر الحاسب الألي المحمول (laptop) فيمكن للمتعلم أن يتعلم

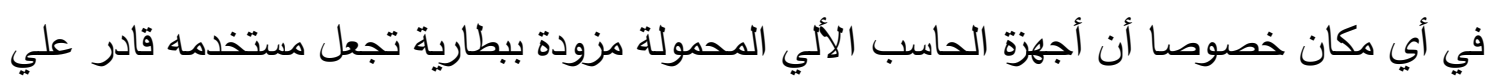

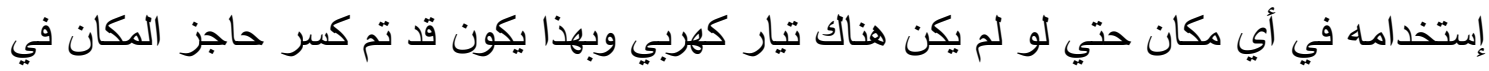

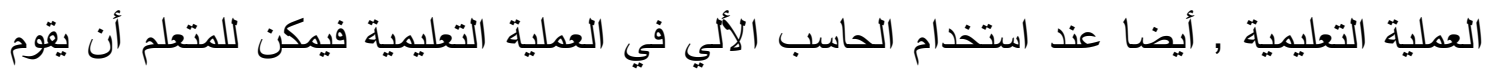
بتثغل البرنامج الخاص بالدرس الذي يريده في أي وقت ومانسب لله وبهذا يكون المتعلم غير مرتبط

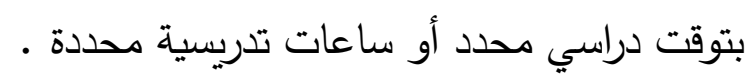

• يوفر الحاسب الألي خاصية المحاكاة (simulation) أصبح ماتح الأن ما يعرف ببرنامج المحاكاة والتي توفر بيئة تماثل البيئة الحقيقية للتجربة المراد

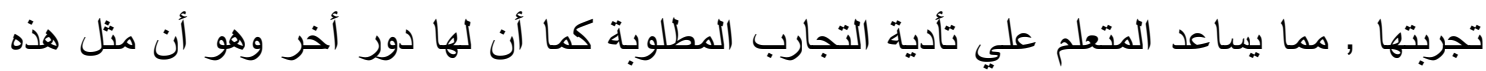
البرامج المتخصصة في المحاكاة تعطي فرصة للباحثين من عمل إختبارات للمراد تطبيقها بثكل

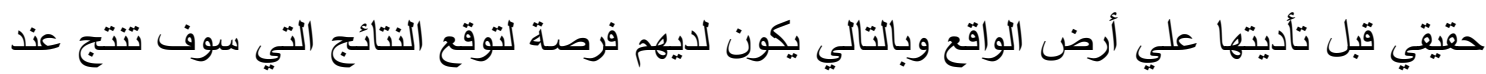
تادية هذه التجربة .

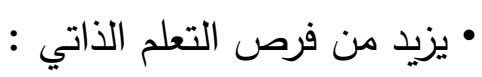
يزيد إستخدام الحاسب الألي من فرص التعلم الذاتي حيث يمكن للمتعلم أن يتعلم بشكل فردي دون

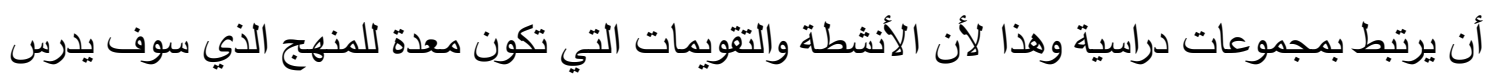

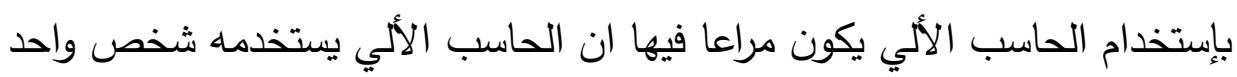

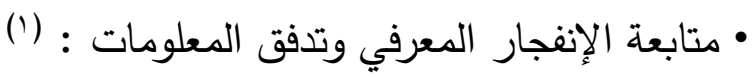
لقد أدي تدفق المعلومات إلي تطور وسائل الإتصالات خاصة إندات إننا نعيش في عصر الإنفجار

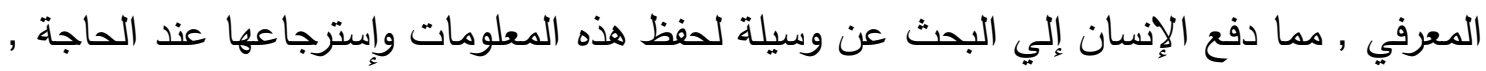

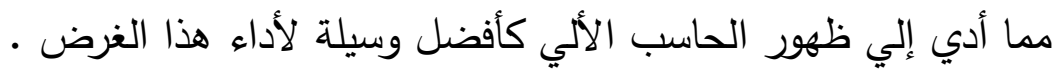

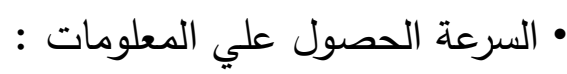
بنا أننا نعيش في عصر السرعة , فنحن بحاجة إلي التعامل مع الكم الهائل من المعلومات , وكلما

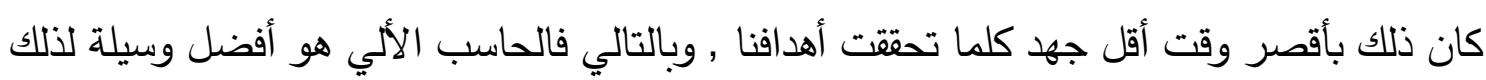
• إيجاد الحلول لمشكلات الصعوبات التعلم :

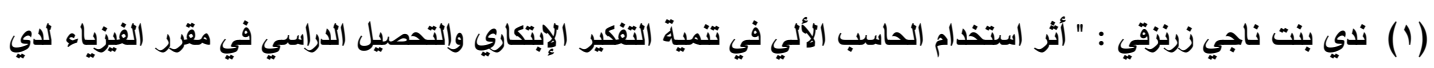

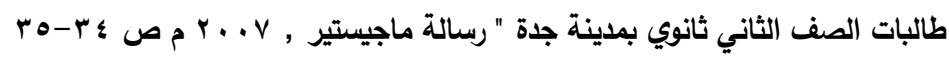

مجلة علوم وفنون الموسيقى - كلية التربية الموسيقية - المجلد الخامس والأربعوذ - يوليو ابr.r. 
أثبتت الدراسات والأبحاث أن الحاسب الألي دورا مهما وكبيرا في المساعدة علي حل مشكلات

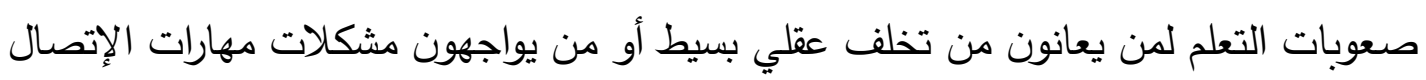
• تتمية مهارات معرفية عقلية عليا :

وتتمثل هذه المهارات في حل المشكلات ومهارات التفكير , ومهارات جمع البيانات وتحليلها وتركيبها

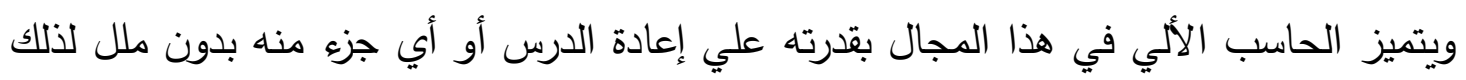

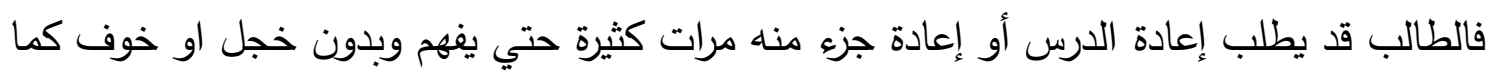

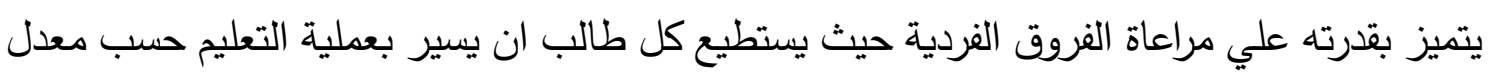

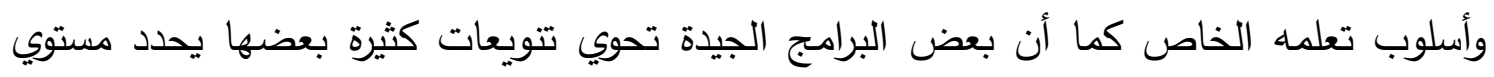

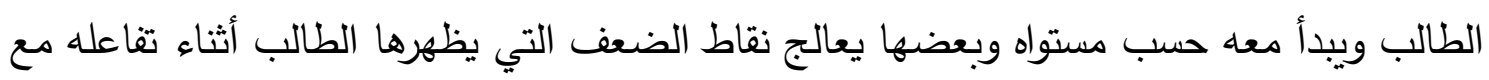

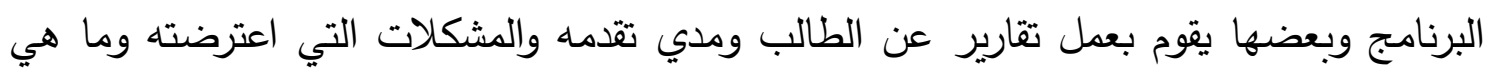
نقاط القوة والضعف لديه إلي غير ذلك من المعلومات الكثيرة التي تهم المدرس , وتمكنه من متابعة ولفي

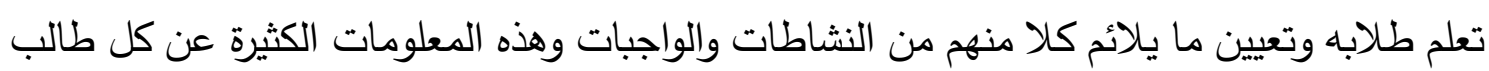
يستحيل المدرس الحصول عليها بدون مساعدة الحاسب الألي .

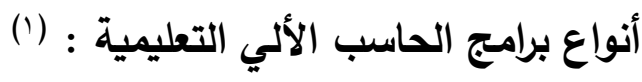
تتعدد أنواع برامج الحاسب الألي التعليمية ومن ثم التوظيف التربوي لكل التبل نوع من تلك البرامج فهنالك

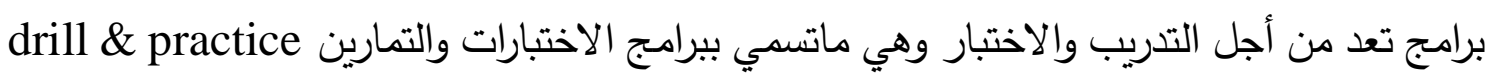

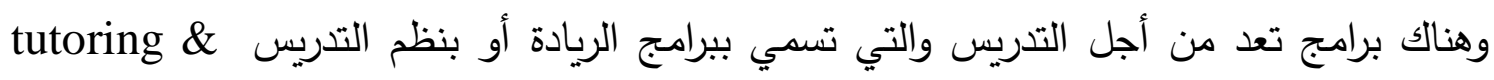
system tutoring system intelligent صنف روسنهاين (Rosenhine1983) العملية التعليمية إلي خمسة أنثطة وهي : ا ب - تقديم المعلومات والتعريف بالمهارات المطلوبة

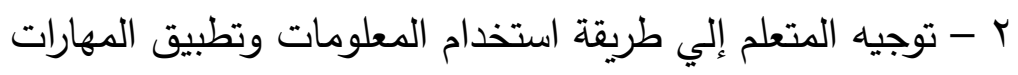
r - معالجة نقاط الضعف في تحصيل المتعلم للمعلومات بطرق أكثر تشويقا ودافعية للعمل ع - التدريب والتمرين لإستيعاب المعلومات وإتقان المهارات ه - تقويم مستوي تحصيل أو أداء المتعلم

(1) أريك هولسينجر : " طيف تعمل الوسائط المتعدة " , ترجمة التعريب والترجمة , بيروت , الدار العربية للعلوم 999 م

مجلة علوم وفنون الموسيقى - كلية التربية الموسيقية - المجلد الخامس والأربعوذ - يوليو ابrrم 


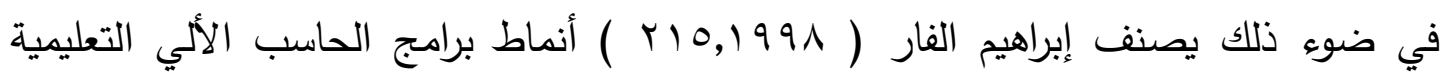
المستخدمة كأنماط للتعلم والتعليم عن طريق الحاسب الألي في ضوه أنثي أنثطة ومراحل العملية التعليمية والتي عرضها روستهان ( Rosenhine ) كالتالي : ندط التدريب الخصوصي

Drill \& practice نمط التدريب والمران problem solving نمط حل المسائل والتمارين

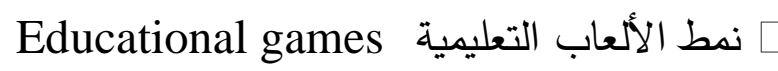
Diagnostic \& proscriptive نمط التشخيص والعلاج

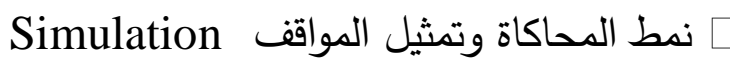
البرنامج : - البرام

هو مجموعة من الخبرات التي تصمم لغرض التعليم والتدريب بطريقة مترابطة من خلال صفات

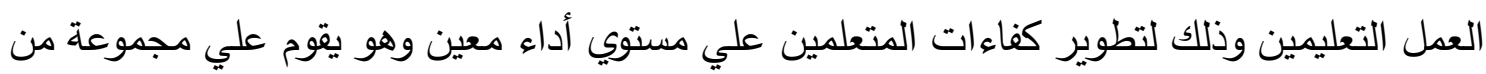

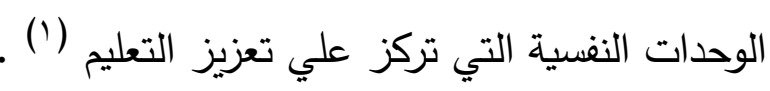
وقد عرف بون Bone البرنامج بانه كل الأنثطة المخططة والمنظمة المصاغة التي تؤثر في تلتئي الإستراتيجيات التربوية والتي تؤدي في النهاية إلي إحداث تغير سلوكي في المتعلمين

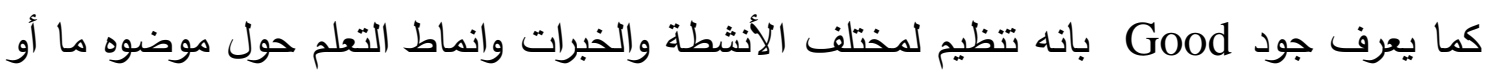

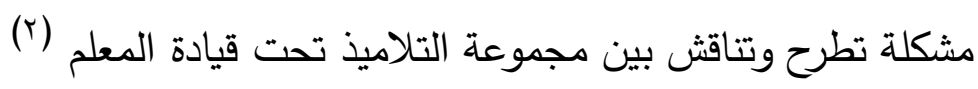

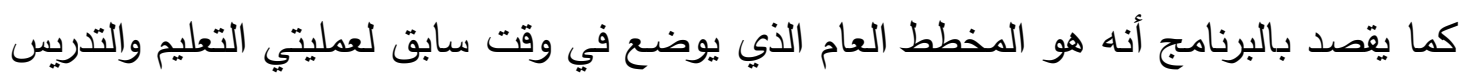

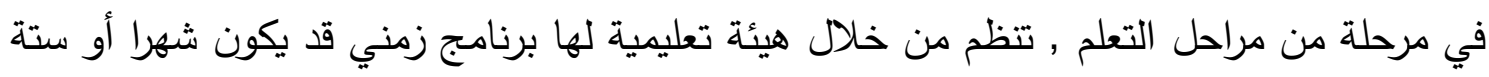

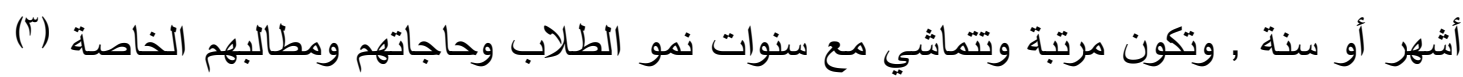

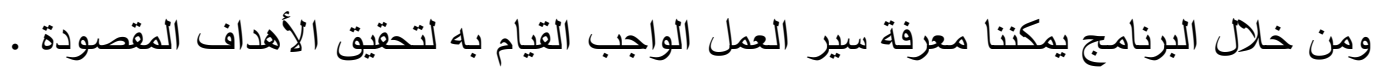
تقنيات العزف على آلة الكمان:

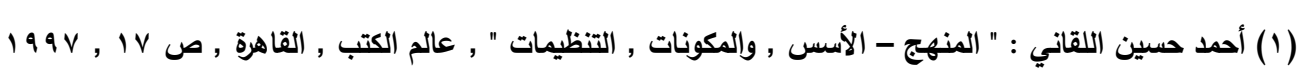

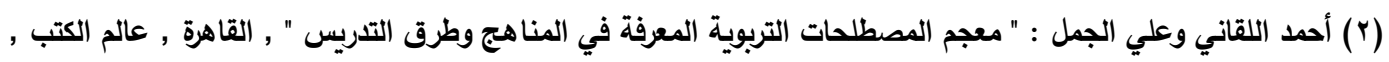

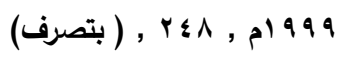

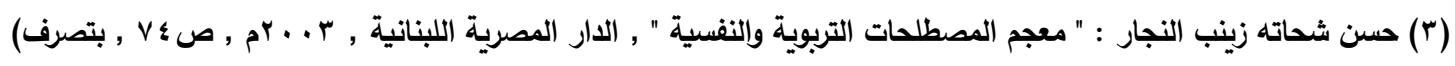


الليجاتو هو عزف نغتتين أو أكثر في ضربة قوس واحد(') ، ويعد الليجاتو من أكثر أشكال الأداء

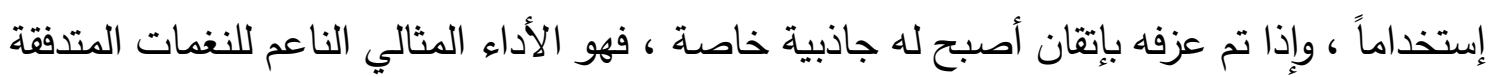

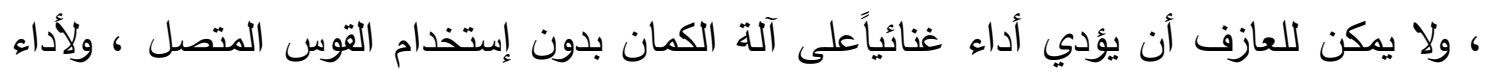

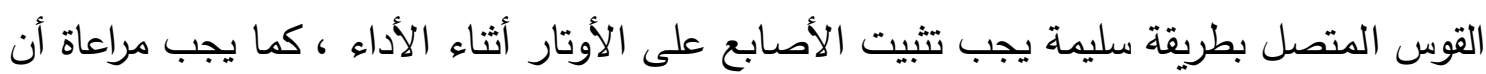
تكون حركة التغيير بين الأوتار في اليد اليمنى غير ملحوظة وبدون أي خشونة (†).

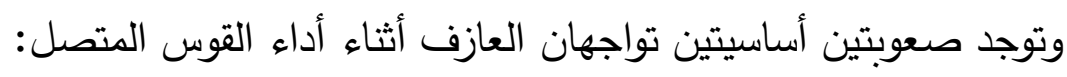
الصعوبة الأولى: تتعلق بتغيير الأوضاع في اليد اليسرى الئون. الصعوبة الثانية: تتعلق بتغيير الأوتار .

وفي الحالة الأولى (التغيير بين الأوضاع) يجب ألا يتأثر القوس بما تفعله اليد اليسرى ، كما أن

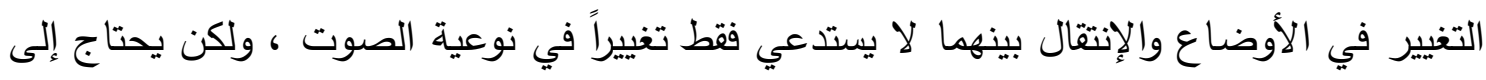

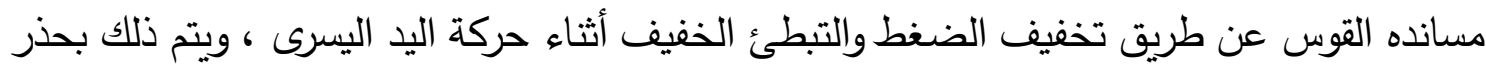

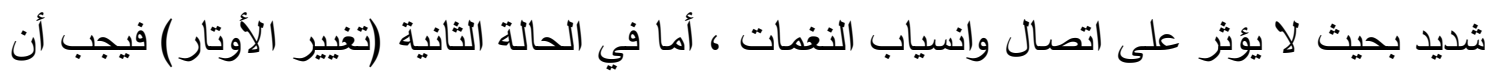

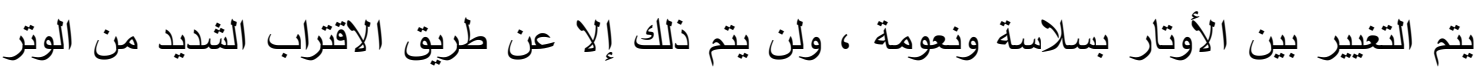

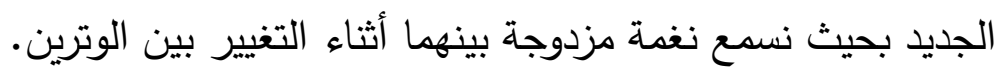

\section{: Detache "القوس المنفصل "ديتاشية *}

هو إصطلاح فرنسي معناه النغمات الغير مربوطة (Non-legato) ، وتعتبر الديتاشية من الأشكال

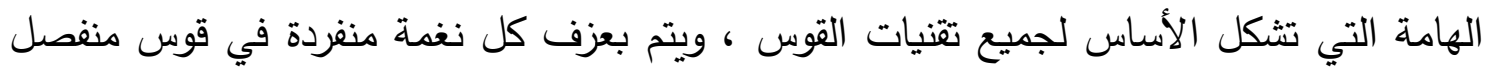

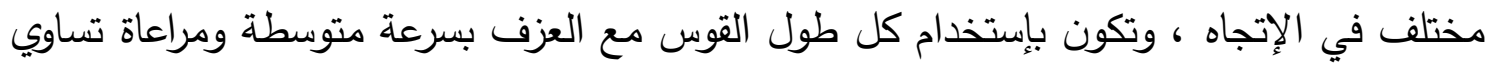

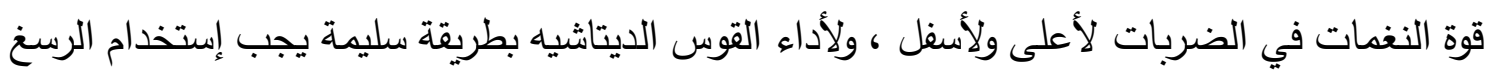

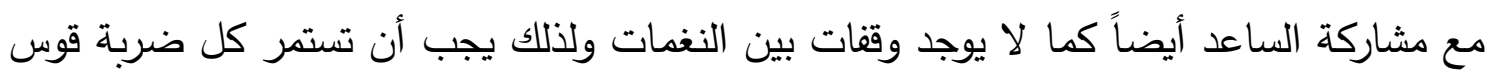

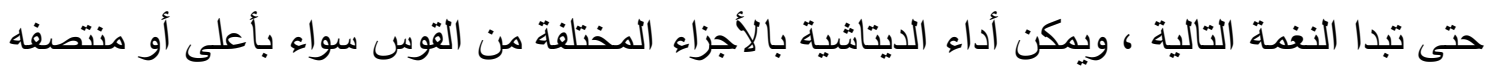
أو من الكعب ، ويرمز للديتاثية بعلامة (-) أسفل النغمات أو أعلاها(؟).

(4) Ivan Galamian : Principles of violin Playing and Teaching Prentice-xall. Inc. Englewood. Cliffs. N.G. , 1962, p. 64.

(5) Lepold Auer: Violin playing as I teach it, New York, Dover Publication, Inc, 1980, p. 31-33

(1) Ivan Galamian: Op. Cit , 1962 , p. 69 
: Martele القوس المطرقة "الثاكوش" المارتيلية" كلمة فرنسية مشتقة من الكلمة الإيطالية مارتيلاتو" Martellato" ومعناها الثاكوش ، والمقصود

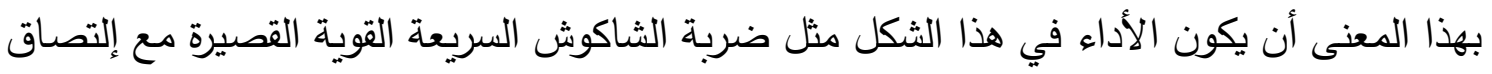

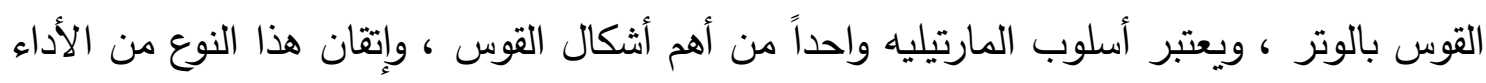

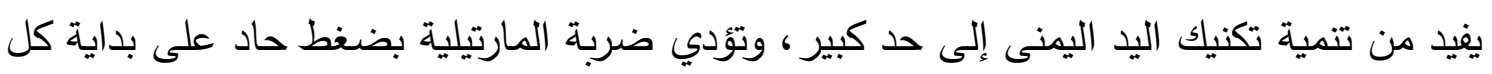

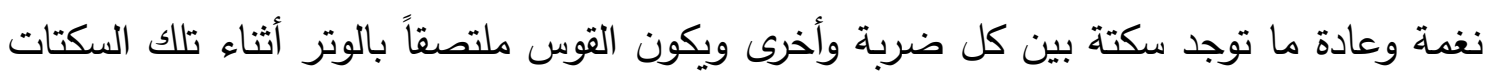

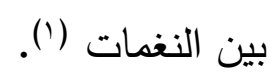
ويوجد نوعان من المارتيليه: المارتيليه القصيرة: ويؤدي بطرف القوس المئيه

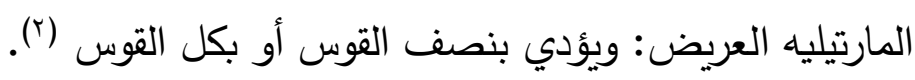
ويعتبر المارتيلية أساس لثكل آخر من أشكال الأداء وهو (الاستكاتو).

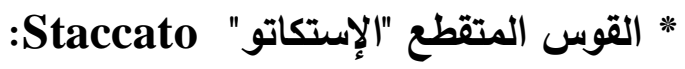
هو صوت متقطع قصير حاد الطابع ، ويؤدي بقوس ثابت على الأوتار ، ويكون في القوس الواحد

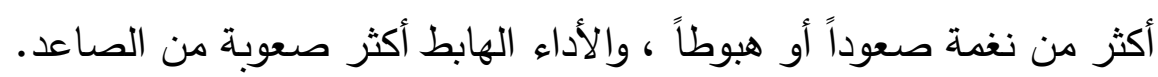

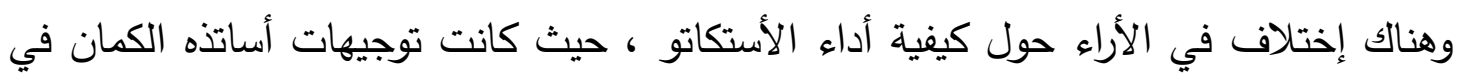

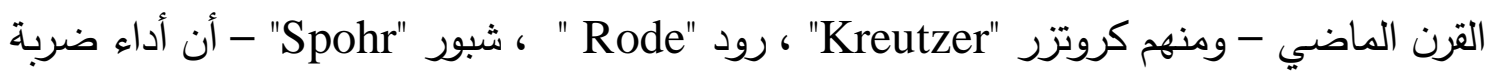

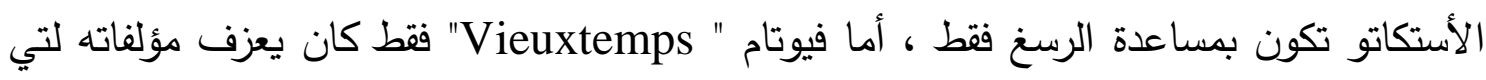

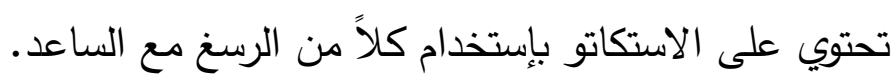
وهنالك نوعان من الاستكاتو:

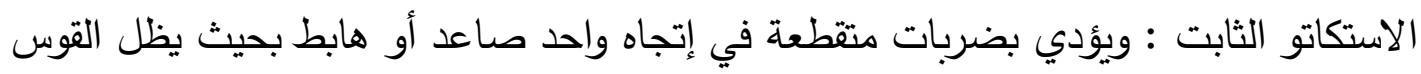

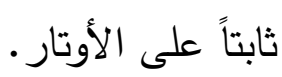
الاستكاتو الطائر : ويؤدي بحيث يكون القوس بعيداً عن الوتر ، أي بدفع القوس على الوتر بضربات

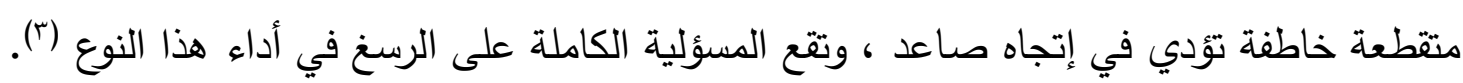

(2) Leopold Auer: Op. Cit , 1980 , P. 26

(1) Ivan Galamian: Op. Cit , 1962 , P. 75

(2) Leopold Auer: Op. Cit , 1980, PP. 27,28

مجلة علوه وفنون الموسيقى - كلية التربية الموسيقية - المجلد الخامس والأربعون - يوليو الr.rم 
* : Spiccatto القوس المتقطع القافز : يستخدم القوس المتقطع في أداء النغمات منفصلة بعضها عن بعض نتيجة وثوب القوس على

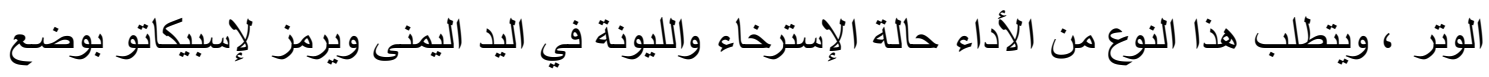

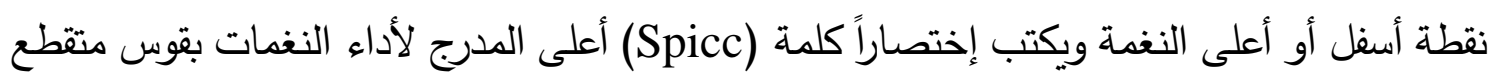

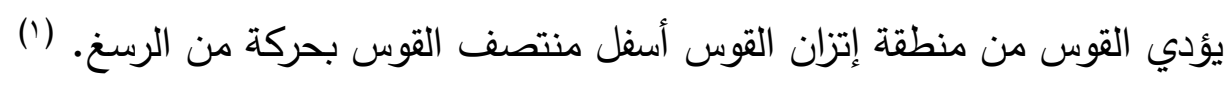
* التريمولو Tremolo:

ويعني بالإيطالية رعشة- ويشار إلى التريمولو بوضع عدة خطوط على ذيل النوته الموسيقية هكذا

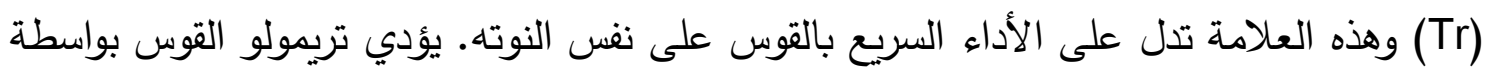

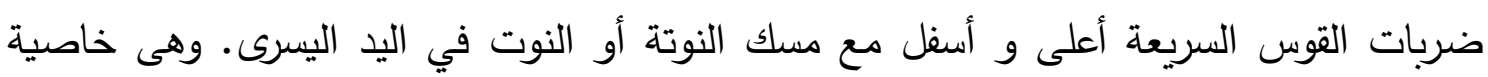

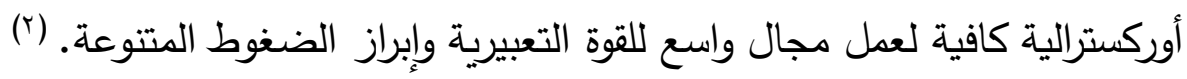
* ثانياً: تقنيات اليا اليسرى:

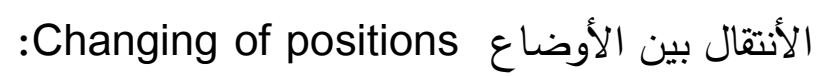
الإنتقال هو عملية تحريك اليد اليسرى بحرية صعوداً أوهبوطاً فوق رقبة الكمان (لوحة الأصابع)

ويوجد نوعان أساسيان من الإنتقال هما (r):

1- الإنتقال الكامل: (Complete shift)

r- الإنتقال الجزئي (half shift)

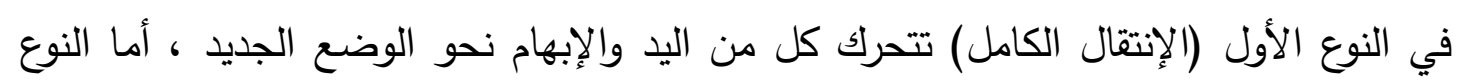

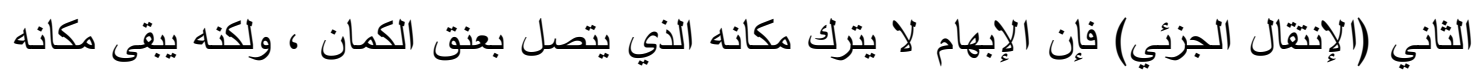

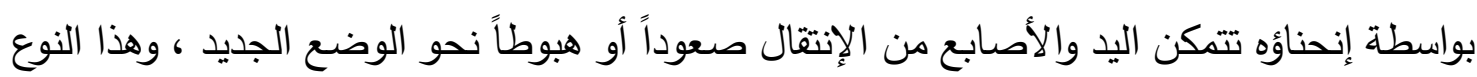

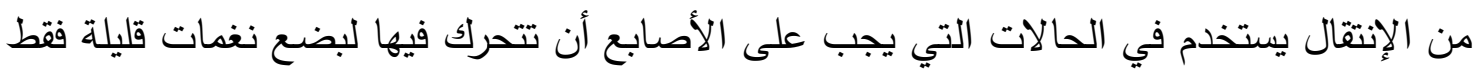
في الوضع الجديد ، ثم تعود للوضع السابق مرة آخرى.

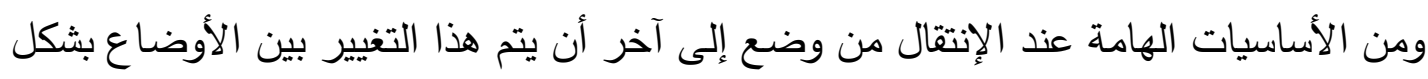
غير مسموع ، أي بدون أن تظهر أصوات أونغمات غير مطلوب سماعها أثناء حدوث الإنتقات الإنقال.

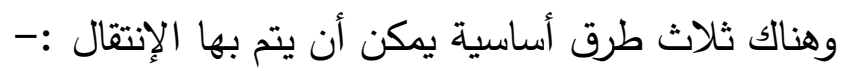

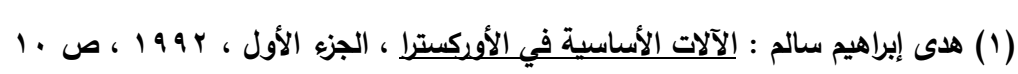

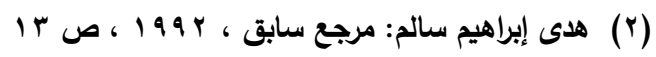

(2) Ivan Galamian: Op. Cit , 1962 , p. 23,24

مجلة علوم وفنون الموسيقى - كلية التربية الموسيقية - المجلد الخامس والأربعون - يوليو الr.rم 
ا-الإنتقال بنفس الأصبع ، بحيث يتم عزف نغمة ما ، ثم عزف نغمة أخرى في وضع جديد بنف

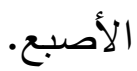
ץ- الإنتقال بالحركة الأنزلاقية Sliding moti ، بحيث يظل الأصبع على الوتر حتى يتم الإنتقال

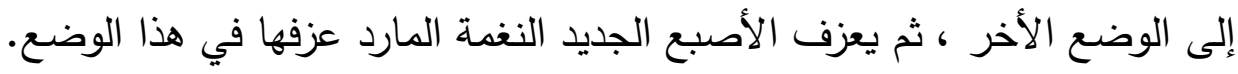
r - الإنتقال بواسطة الأصبع المارد عزف النغمة الجديدة به.

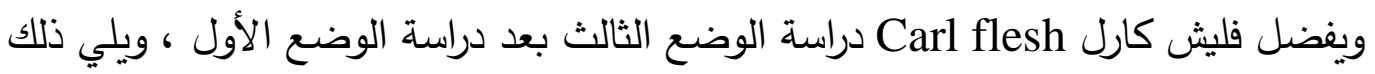

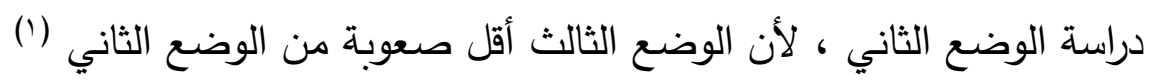
الإطار التطيقيقى

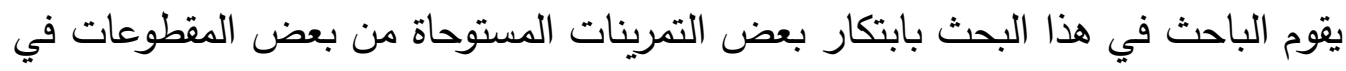
منهج الفرقة الأولي بالترم الثاني وذلك لتحسين مستوي الأداء علي آلة الكمان.

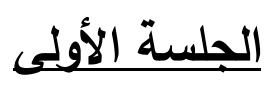

مدة الجلسة : 0ـ دقيقة

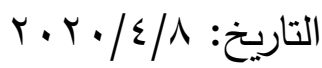
موضوع الجلسة : ( التعرف علي برنامج Zoom - أداء سلم لا الكبير والاربيج - أداء تمرين مستوحي من مقطوعة توينكل Twinkle للتعرف علي الأساليب المختلفة للقوس ). تنفيذ الجلسة : التمهيد : لأنيل

- يقوم الباحث بتعريف الطلاب عينة البحث ببرنامج Zoom وإمكانيات استخدامة من خلال جهاز

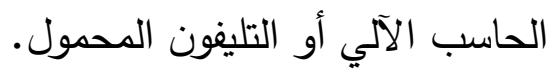
"Suzuk Violin من كتاب سوزوكي Twinkle يستمع الطلاب الى مقطوعة تونكيل Method-Vol 01"

(1) Carl Flash: the art of violin playing , bookone, Newyourk, 1939, P. 26 مجلة علوم وفنون الموسيقى - كلية التربية الموسيقية - المجلد الخامس والأربعوذ - يوليو ابr.r. 


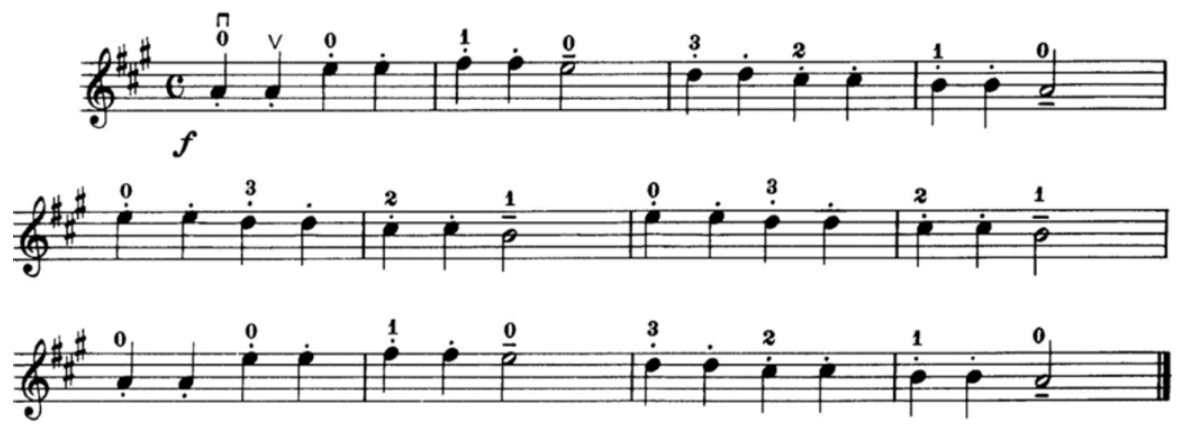

شكل رقم (1) يوضح مقطوعة تونكيل

"Suzuk Violin Method-Vol 01” من كتاب سوزوكي

- يتم عزف سلم لا الكبير والأربيج بالثكل التالي :
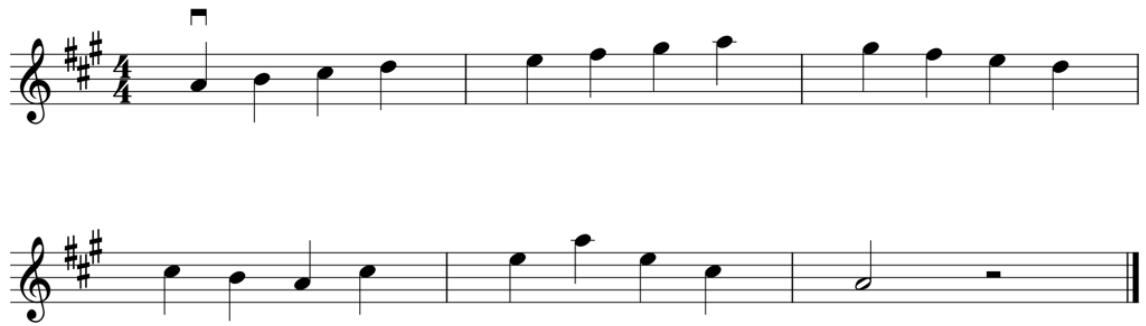

شكل رقم (r) يوضح سلم لا الكبير والاربيج

\section{الجلسة الثانية}

مدة الجلسة : 0؟

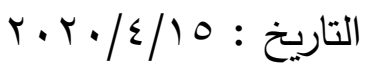

دقيقة

موضوع الجلسة : ( أداء سلم لا الكبير والاربيج - أداء تمرين مستوحي من الجزء الأول من مقطوعة ليتلي رو Lightly Row ).

تنفيذ الجلسة : n

التمهيد : - الت

- يستمع الطلاب الى الجزء الأول من مقطوعة ليتلي رو Lightly Row من كتاب سوزوكي "Suzuk Violin Method-Vol 01" 


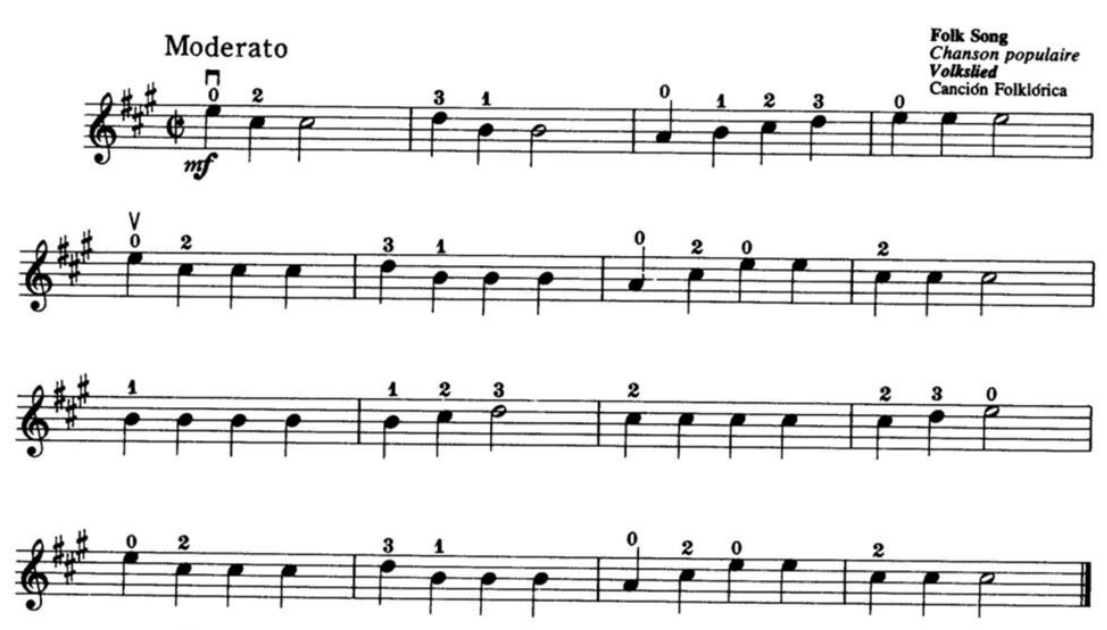

شكل رقم (r) يوضح مقطوعة ليتلي رو Lightly Row

من كتاب "Suzuk Violin Method-Vol 01"

- يتم عزف سلم لا الكبير والأربيج.

- يتم عزف تمرين مستوحى من الجزء الاول من مقطوعة ليتلي رو Lightly Row، وهو عبارة عن النغمات الأساسية لسلم لا الكبير .
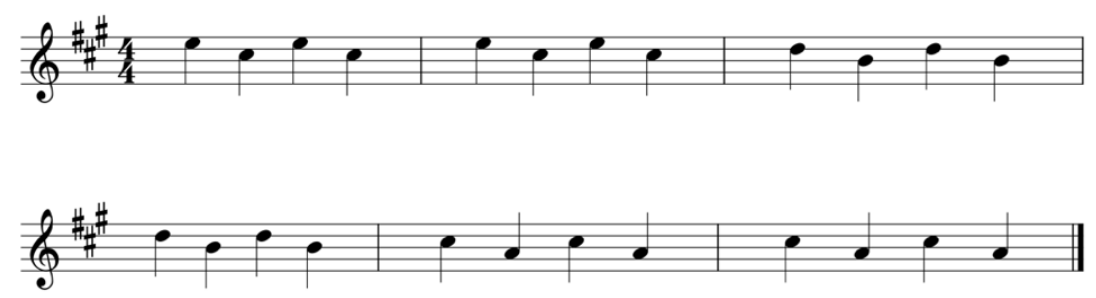

شكل رقم (؛) يوضح بدريب مستوحي من الجزء الأول من مقطوعة ليتلي رو Lightly Row

من كتاب سوزوكي "Suzuk Violin Method-Vol 01 "

شرح التمرين :

- التدريب علي أداء مسافة ץ ك مع عبور القوس بطريقة مناسبة.

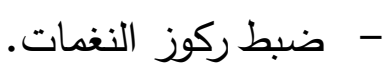
- - - - يؤدي التمرين بالقوس الديتاشيه. - التدريب على العزف في ميزان ( 4 التقويم :

وجد الباحث أن بعض الطلاب غير قادرين علي التتقل بين الاوتار بحرية، ولكن مع توجيه

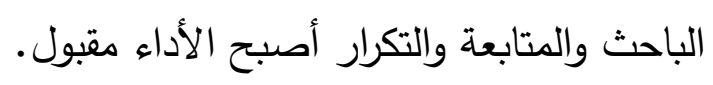

مجلة علوه وفنون الموسيقى - كلية التربية الموسيقية - المجلد الخامس والأربعوذ - يوليو ابrمه 


$$
\text { التعليق على الجلسة : التبة }
$$

الجلسة كانت هادفة ومشوقة خاصة مع استخدام التدريس عن بعد من خلال برنامج Zoom،

$$
\text { مع إلتزام الطلاب بالحضور • ماند }
$$

\section{الجلسة الثالثة}

مدة الجلسة : 0ـ دقيقة

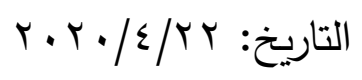

- موضوع الجلسة : ( أداء سلم لا الكبير والاربيج - الجزء الثاني من مقطوعة ليتلي رو

( Lightly Row

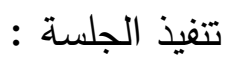

التمهيد :

- يتم عزف سلم لا الكبير والأربيج.

- - يستمع الطلاب الى الجزئ الثاني من مقطوعة ليتلي رو Lightly Row من كتاب

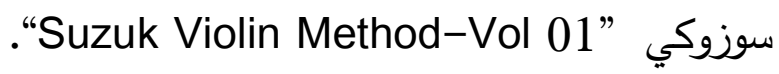
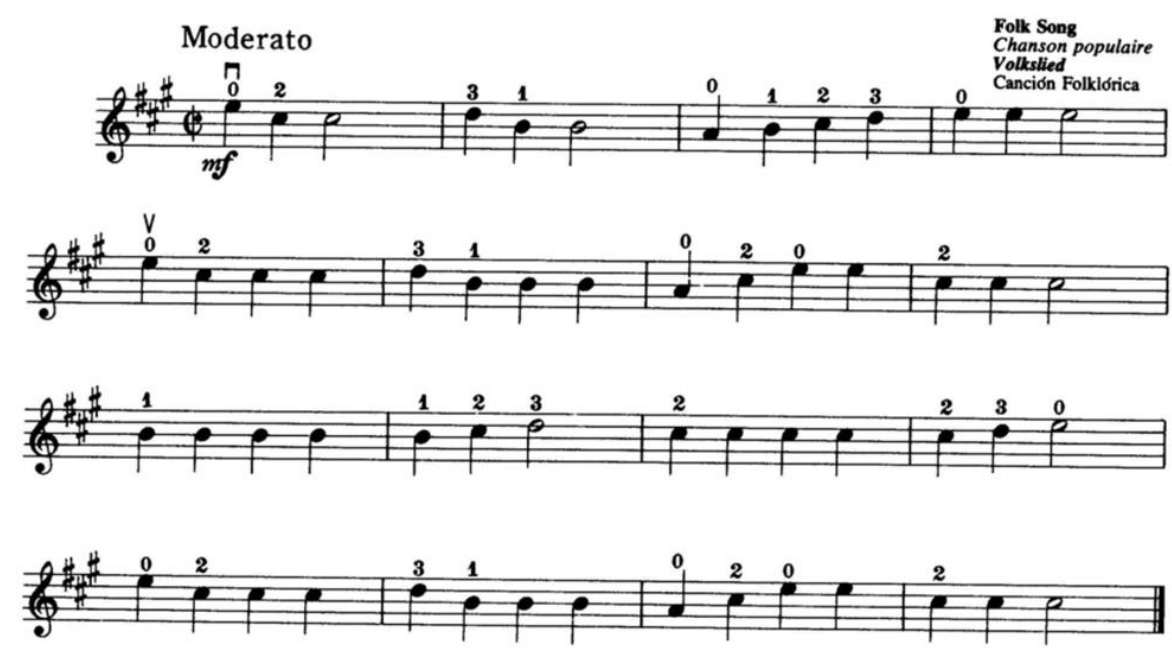

شكل رقم (0) يوضح دراسة الجزئ الثاني من مقطوعة ليتلي رو Lightly Row

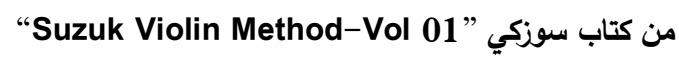

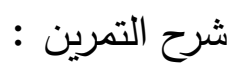

- - التأكد من ضبط ركوز النغمات. - - التدريب على القوس العريض الصاعد والهابط.

$$
\text { - التدريب على العزف في ميزان (4) - }
$$


وجد الباحث أن هناك تقدم الطلاب في أداء القوس وعبوره علي الاوتار .

$$
\text { التعليق على الجلسة : التمان }
$$

الجلسة كانت هادفة ومشوقة خاصة مع استخدام التدريس عن بعد من خلال برنامج Zoom، مع

$$
\text { إلتزام الطلاب بالحضور · مانه }
$$

\section{الجلسة الرابعة}

$$
\begin{aligned}
& \text { مدة الجلسة : 0ـ دقيقة }
\end{aligned}
$$

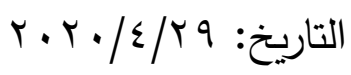

$$
\begin{aligned}
& \text { موضوع الجلسة : ( أداء سلم لا الكبير والاربيج - أداء تمرين مستوحي من الجزء الأول من } \\
& \text { (Song of the Wind مقطوعة سونج اوف ويند } \\
& \text { تنفيذ الجلسة : } \\
& \text { : التمهيد }
\end{aligned}
$$

- يستمع الطلاب الى الجزء الأول من مقطوعة Song of the Wind من كتاب سوزوكي .Suzuk Violin Method-Vol 01"

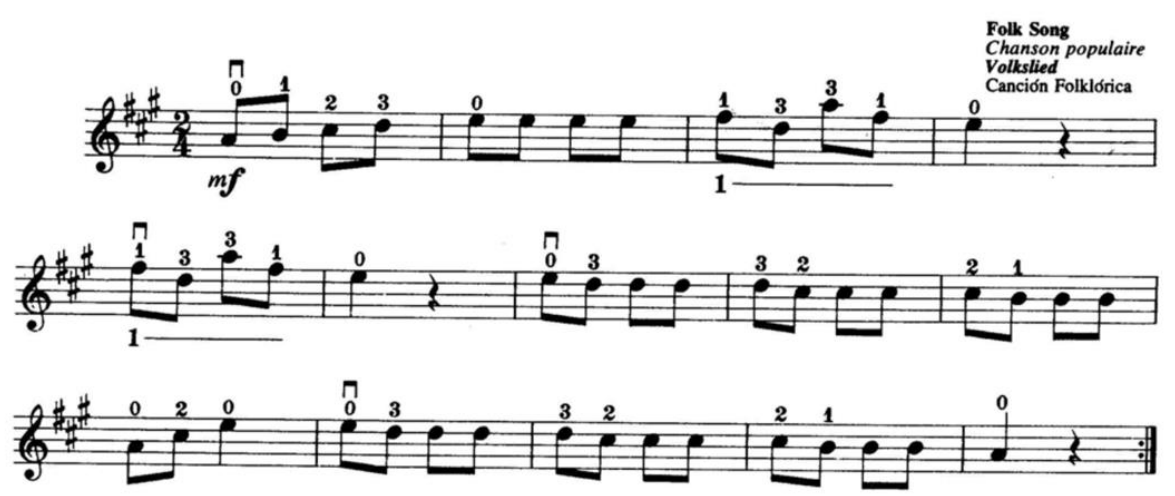

Song of the Wind شكل رقم (†) يوضح دراسة الجزء الأول من مقطوعة

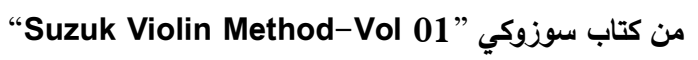

$$
\text { - يتم عزف سلم لا الكبير والأربيج. }
$$

- يتم عزف تمرين مستوحى من الجزء الأول من مقطوعة Song of the Wind، وهو عبارة عن النغمات الأساسية لسلم لا الكبير • 

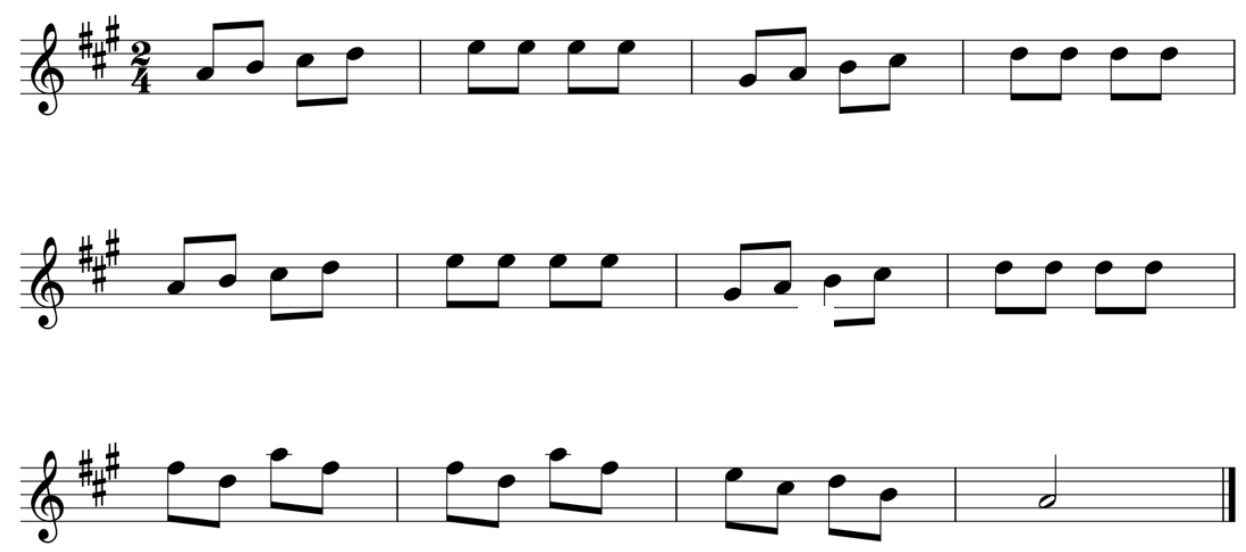

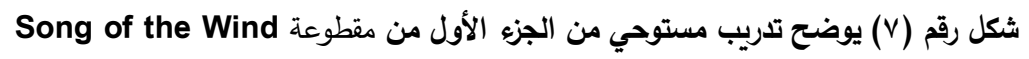

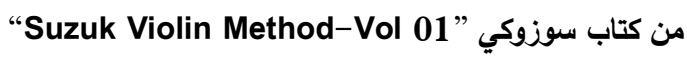

$$
\text { شرح التمرين : (التبن }
$$

- - التدريب علي أداء نغمات في لحن متصاعد. - التدريب علي أداء مسافة ץ ك مع عبور القوس بطريقة مناسبة.

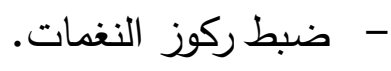

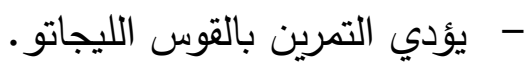
- التدريب على العزف في ميزان ( 2 التقويم :

وجد الباحث أن بعض الطلاب غير قادرين علي التتقل بين الاوتار بحرية، ولكن مع توجيه

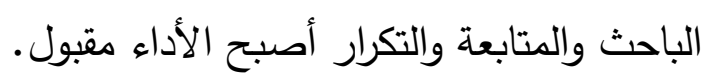

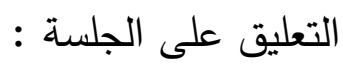
الجلسة كانت هادفة ومشوقة خاصة مع استخدام التدريس عن بعد من خلال برنامج Zoom، مع

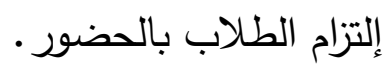

\section{الجلسة الخامسة}

مدة الجلسة : 0؛ دقيقة

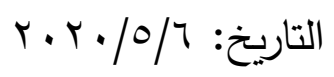

موضوع الجلسة : ( أداء سلم لا الكبير والاربيج - أداء تمرين مستوحي من الجزء الثاني من

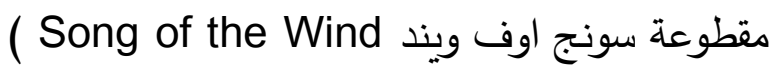
تنفيذ الجلسة :

مجلة علوم وفنوذ الموسيقى - كلية التربية الموسيقية - المجلد الخامس والأربعون - يوليو اب.rم 
- يتم عزف سلم لا الكبير والأربيج كما بالثكل السابق. - - يستمع الطلاب الى الجزء الثاني من مقطوعة Song of the Wind من كتاب

سوزوكي "Suzuk Violin Method-Vol 01.
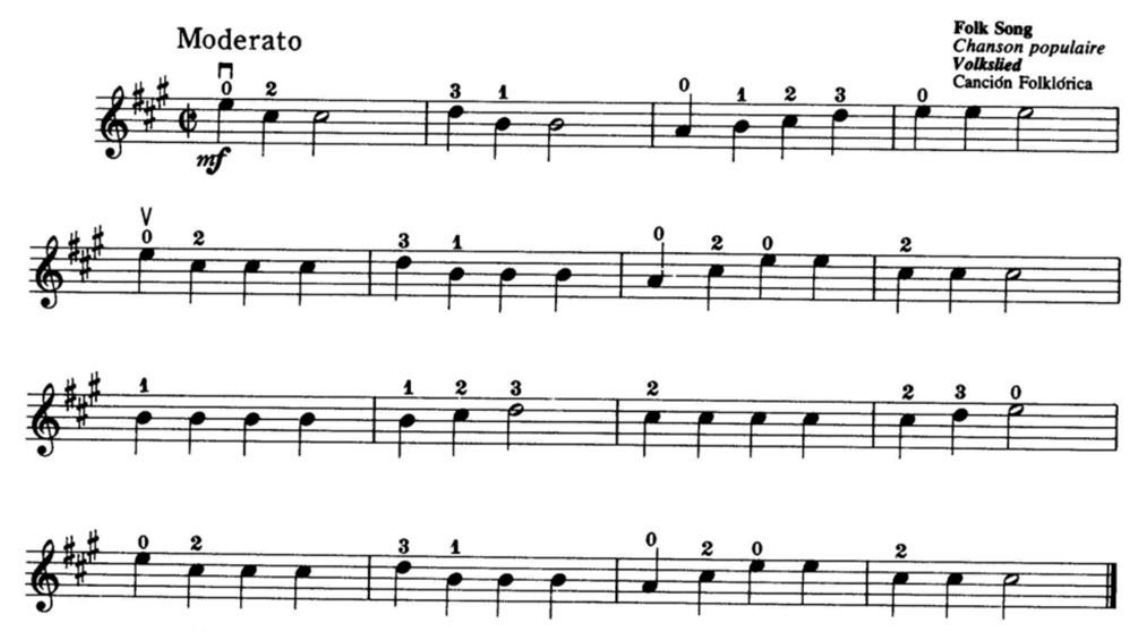

Song of the Wind شكل رقم (^) يوضح دراسة الجزء الثاني من مقطوعة

من كتاب سوزوكي "Suzuk Violin Method-Vol 01

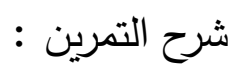

- - التأكد من ضبط ركوز النغمات.

- - التدريب على القوس العريض الصاعد والهابط.

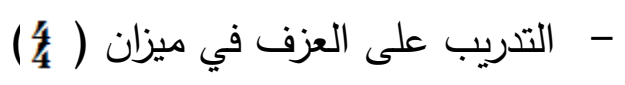
التقويم :

وجد الباحث أن بعض الطلاب غير قادرين علي الأداء بشكل مناسب، ولكن مع توجيه الباحث

$$
\text { والمتابعة والتكرار أصبح الأداء مقبول. }
$$

التعليق على الجلسة :

الجلسة كانت هادفة ومشوقة خاصة مع استخدام التدريس عن بعد من خلال برنامج Zoom، مع

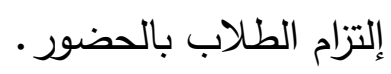




\section{الجلسة السادسة}

مدة الجلسة : 0 مـ دقيقة

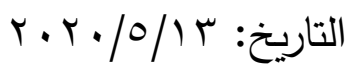

موضوع الجلسة : ( أداء سلم لا الكبير والازبيج - أداء تمرين مستوحي من الجزء الأول من مقطوعة

( Go Tell Aunt Rhody

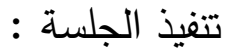

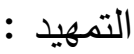

- يتم عزف سلم لا الكبير والأربيج.

- يستمع الطلاب الى الجزء الأول من مقطوعة Go Tell Aunt Rhod من كتاب سوزوكي "Suzuk Violin Method-Vol 01"

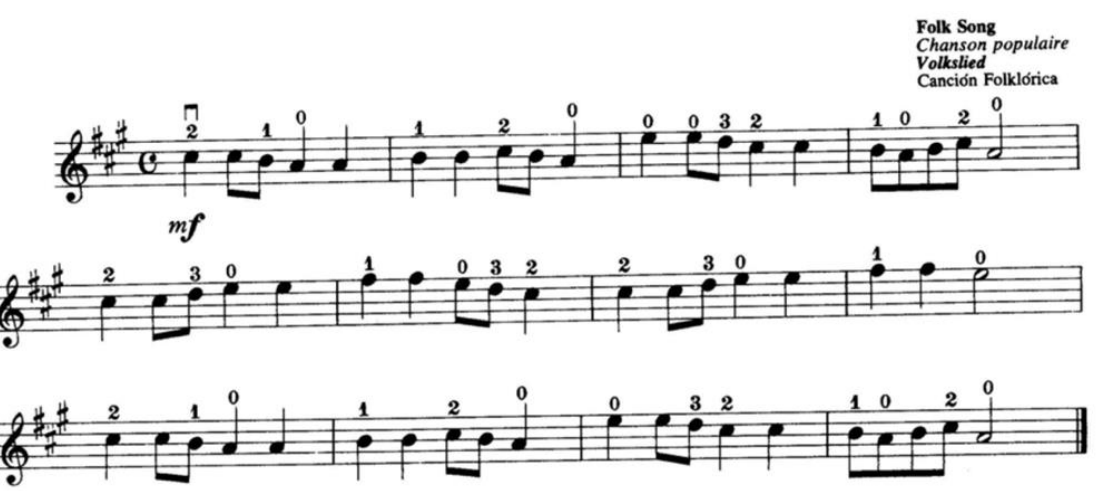

Go Tell Aunt Rhod شكل رقم (9) يوضح دراسة الجزء الأول من مقطوعة

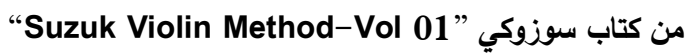

- يتم عزف تمرين مستوحى من الجزء الأول من مقطوعة Go Tell Aunt Rhod.
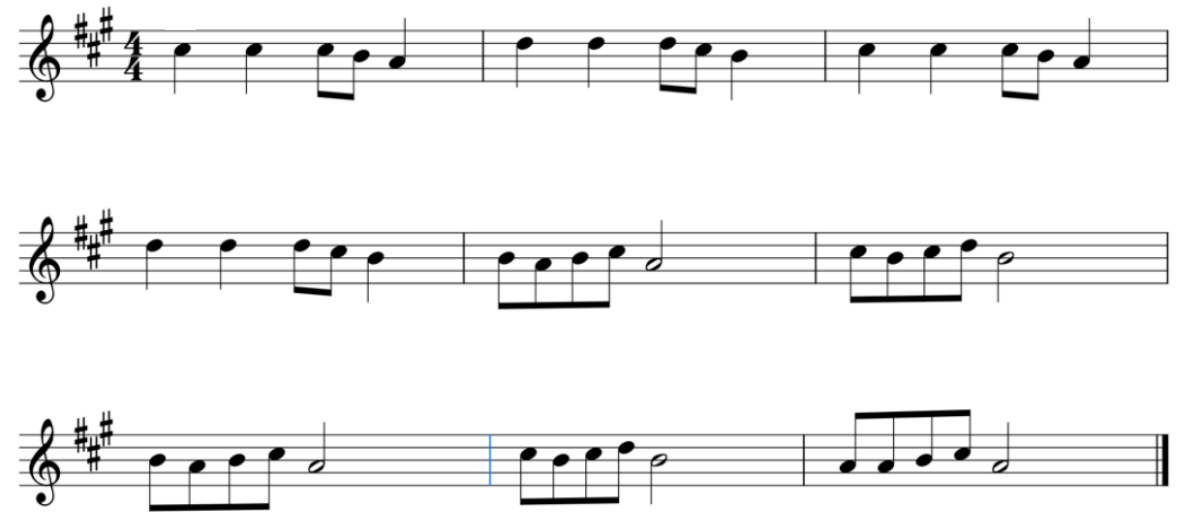

Song of the Wind شكل رقم ( • () يوضح تمرين مستوحي من الجزء الأول من مقطوعة

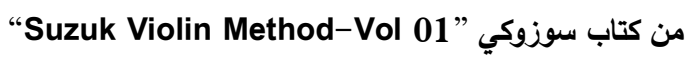

مجلة علوم وفنون الموسيقى - كلية التربية الموسيقية - المجلد الخامس والأربعوز - يوليو الr.rم 


$$
\text { شرح التمرين : (لت }
$$

- التدريب علي الاشكال الايقاعية لتمهيد عزفها بالتمرين. - - التأكد من ضبط ركوز النغمات. - -

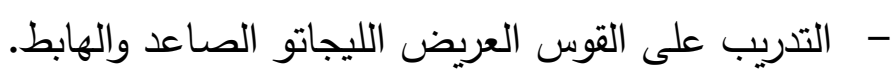
- التدريب على العزف في ميزان ( 4 (4). التقويم :

وجد الباحث أن بعض الطلاب غير قادرين علي التنقل بين الاوتار بحرية، ولكن مع توجيه الباحث والمتابعة والتكرار أصبح الأداء مقبول.

$$
\text { التعليق على الجلسة : ولكتابعة ولكرات }
$$

الجلسة كانت هادفة ومشوقة خاصة مع استخدام التدريس عن بعد من خلال برنامج Zoom،

$$
\text { مع إلتزام الطلاب بالحضور • مانفة }
$$

\section{الجلسة السابعة}

مدة الجلسة : 0؛ دقيقة

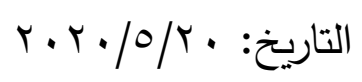

موضوع الجلسة : ( أداء سلم لا الكبير والاربيج - أداء تمرين مستوحاه من الجزء الثاني من

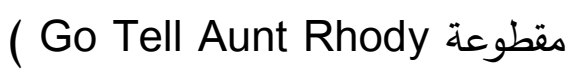

تنفيذ الجلسة : التمهيد :

- يتم عزف سلم لا الكبير والأربيج. - يستمع الطلاب الى الجزء الثاني من مقطوعة Go Tell Aunt Rhody من كتاب سوزوكي "Suzuk Violin Method-Vol 01" 


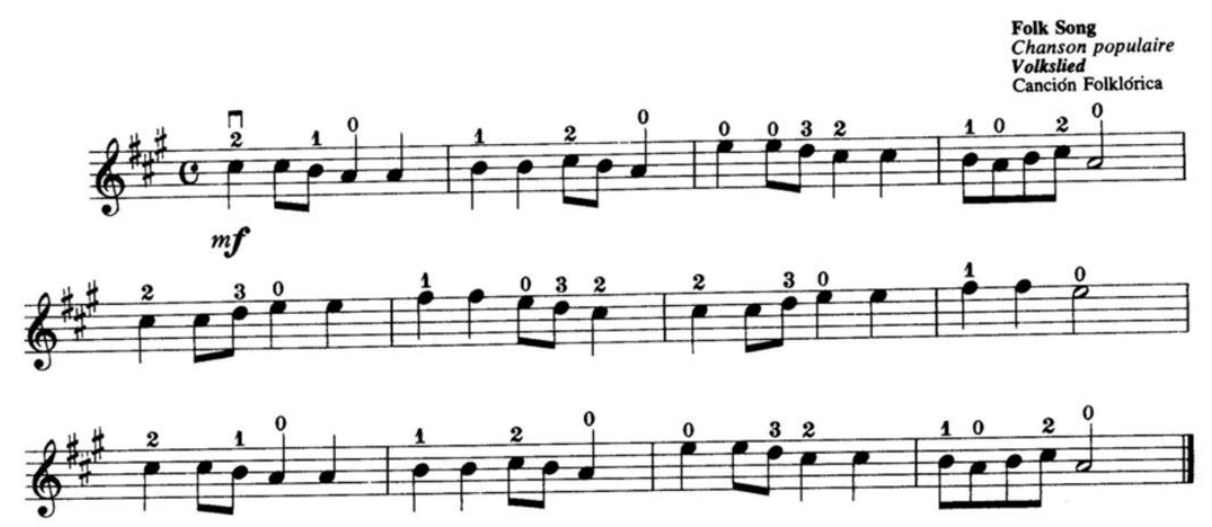

Go Tell Aunt Rhody شكل رقم (11) يوضح دراسة الجزء الثاني من مقطوعة

من كتاب سوزوكي ”Suzuk Violin Method-Vol 01"

$$
\begin{aligned}
& \text { شرح التمرين : } \\
& \text { - التدريب علي أداء نغمات في لحن متصاعد. } \\
& \text { - - التدريب علي أداء. }
\end{aligned}
$$

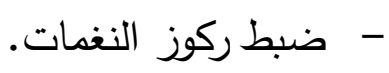

$$
\begin{aligned}
& \text { - يؤدي التمرين بالقوس الليجاتو - } \\
& \text { - التدريب على العزف في ميزان (4 أ ). } \\
& \text { التقويم : }
\end{aligned}
$$

وجد الباحث أن بعض الطلاب غير قادرين علي الأداء بثكل مناسب، ولكن مع توجيه الباحث

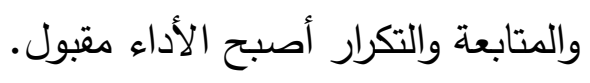$$
\text { التعليق على الجلسة : التحل }
$$

الجلسة كانت هادفة ومشوقة خاصة مع استخدام التدريس عن بعد من خلال برنامج Zoom، مع

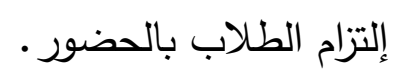

\section{الجلسة الثامنة}

مدة الجلسة : 0ـ دقيقة

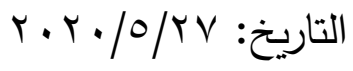

موضوع الجلسة : التدريب علي حصر بعد النصف تون بين الأصبع الأول والثاني ووضع الأصبع . لألع

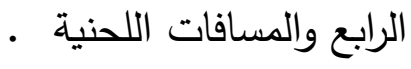


- يستمع الطلاب الى الجزء الأول من مقطوعة رقم (Y0) من كتاب THE Little Sevcik
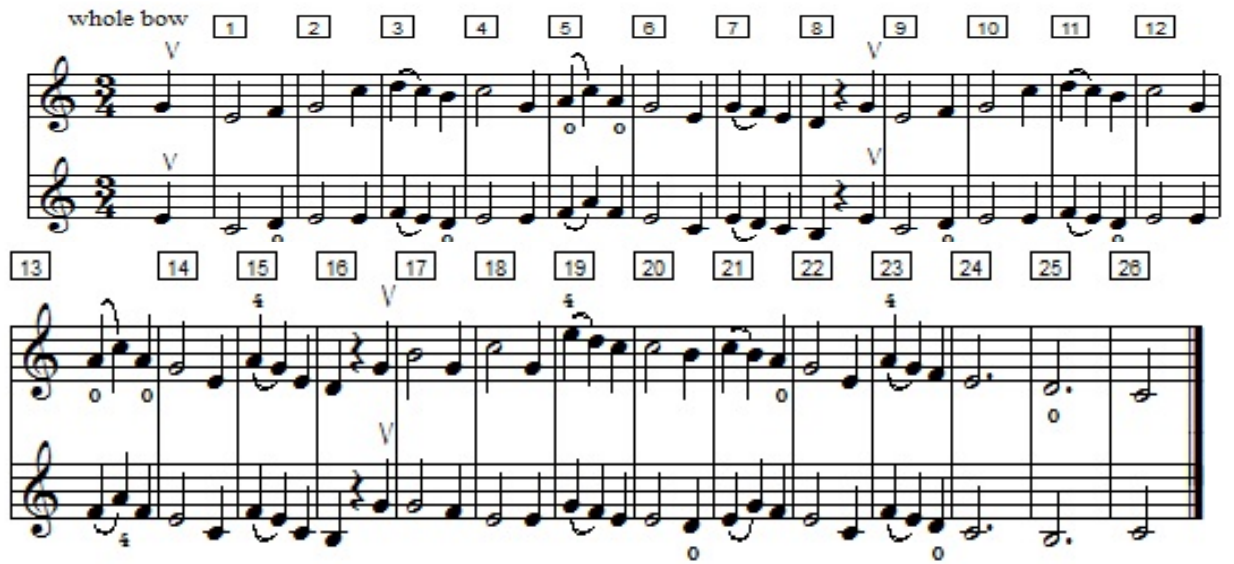

شكل رقم (Y I ) يوضح دراسة الجزء الأول من مقطوعة رقم هץ من كتاب THE Little Sevcik

- يتم عزف سلم دو الكبير وأربيجه بالشكل التالي :
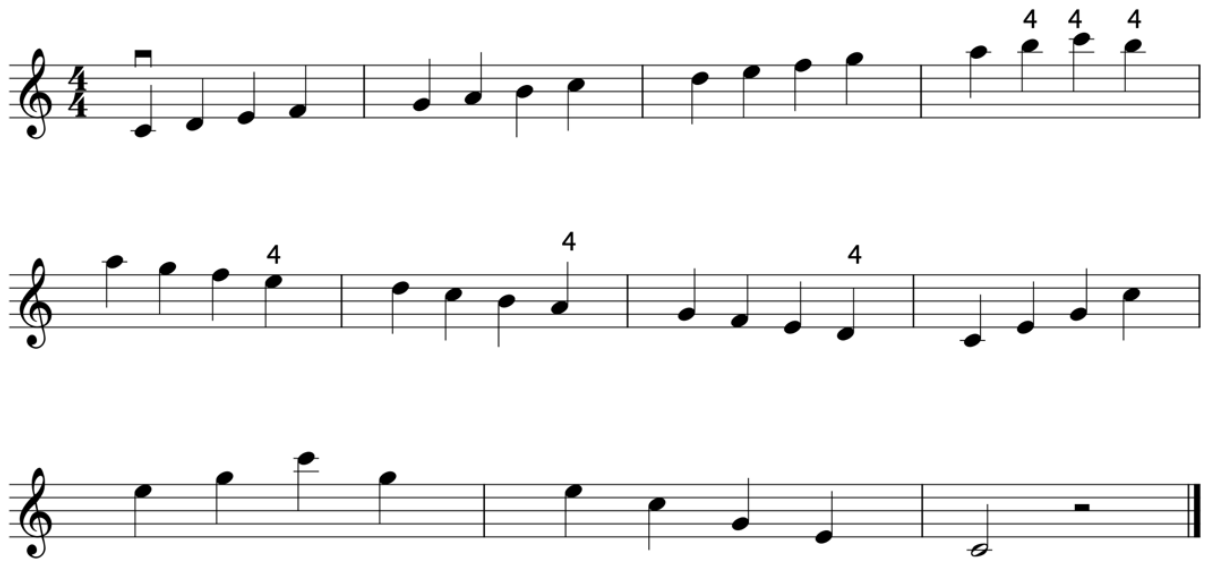

شكل رقم (ז ا) يوضح سلم دو الكبير r اوكتاف والاربيج

- يتم عزف تمرين مستوحى من الجزء الأول من مقطوعة رقم (Y0) ، وهو عبارة عن النغمات الأساسية لسلم دو الكبير •
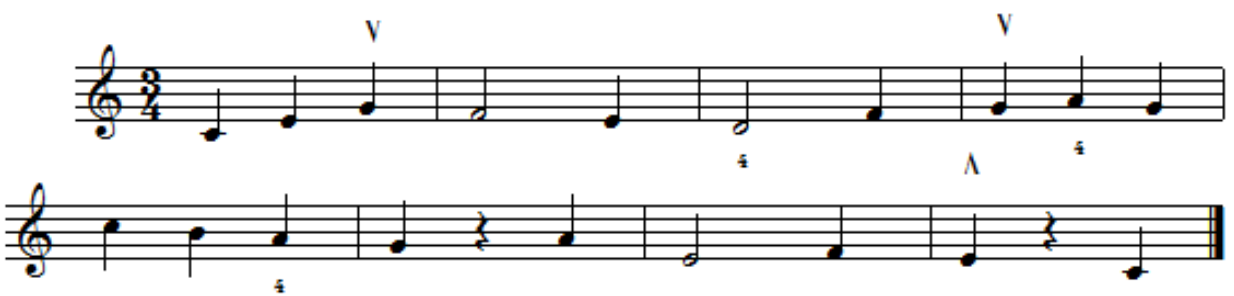

مجلة علوه وفنوز الموسيقى - كلية التربية الموسيقية - المجلد الخامس والأربعوز - يوليو ابr.rم 
شكل رقم (ع () يوضح تمرين مستوحي من الجزء الأول من مقطوعة رقم (Y0) من كتاب سوزوكي THE Little Sevcik شرح التمرين : - التدريب على الأقواس المنفصلة ”Detache“ والأقواس المتصلة ”Legato Bowing" والأقوس الكاملة "Whole Bow"

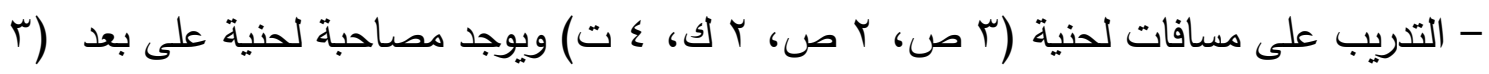

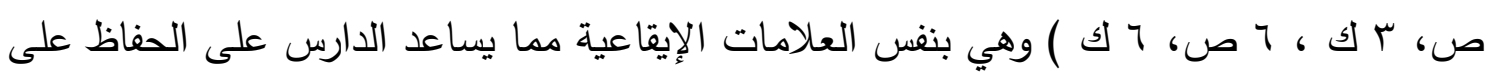

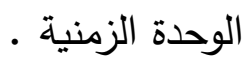

$$
\text { - - التدريب على العزف في ميزان ( } 3 \text { ( }
$$
التقويم :

وجد الباحث أن بعض الطلاب يعزفون نغمات غير سليمة أثناء أداء سلم دو الكبير ، ولكن مع توجيه الباحث ووضع الأصابع فى الأماكن الصحيحة والمتابعة والتكرار أصبح الأداء جيداً.

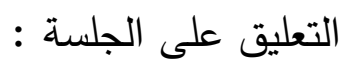
الجلسة كانت هادفة ومشوقة خاصة مع استخدام التدريس عن بعد من خلال برنامج Zoom، مع

$$
\text { إلتزام الطلاب بالحضور • - مان }
$$

\section{الحسةة التاسعة}

مدة الجلسة : 0 0 دقيقة

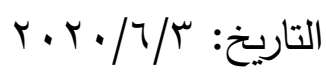

موضوع الجلسة : التدريب علي حصر بعد النصف تون بين الأصبع الأول والثاني ووضع الأصبع • الرابع والمسافات اللحنية تنفيذ الجلسة : : ب. التمهيد

- يستمع الطلاب الى الجزء الثاني من مقطوعة رقم (ب0) من كتاب THE Little -

Sevcik

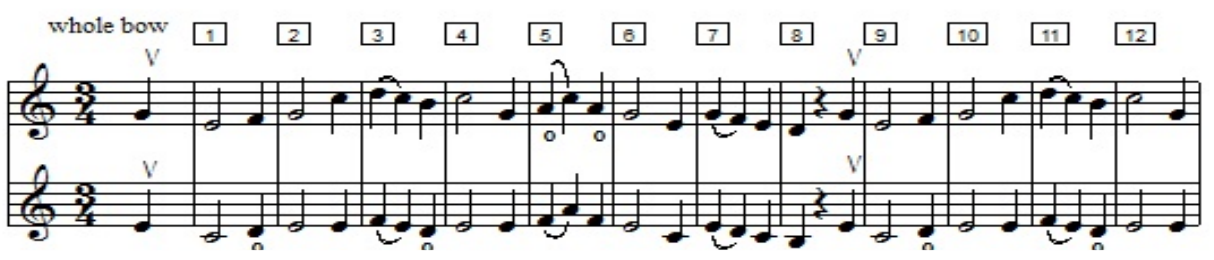




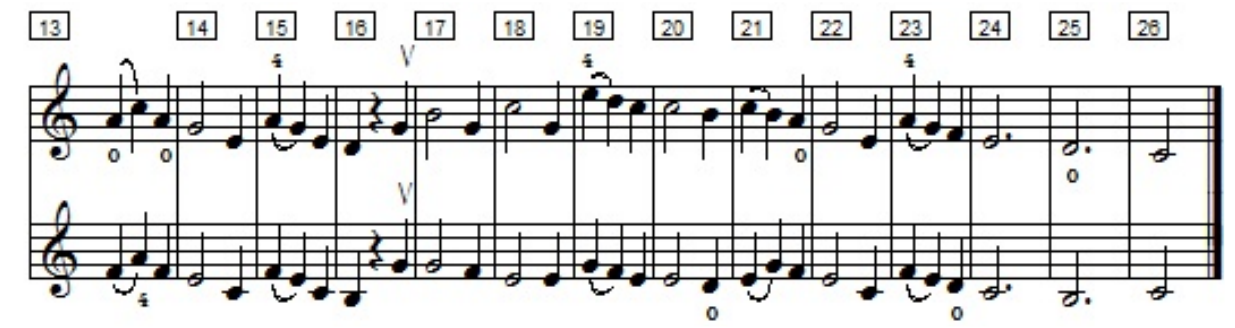

شكل رقم (0 1 ) يوضح الجزء الثاني من مقطوعة رقم هب من كتاب سوزوكي THE Little Sevcik - يتم عزف سلم دو الكبير وأربيجه. - يتم عزف تمرين مستوحى من الجزء الثاني من مقطوعة رقم (Y0) ، وهو عبارة عن النغمات

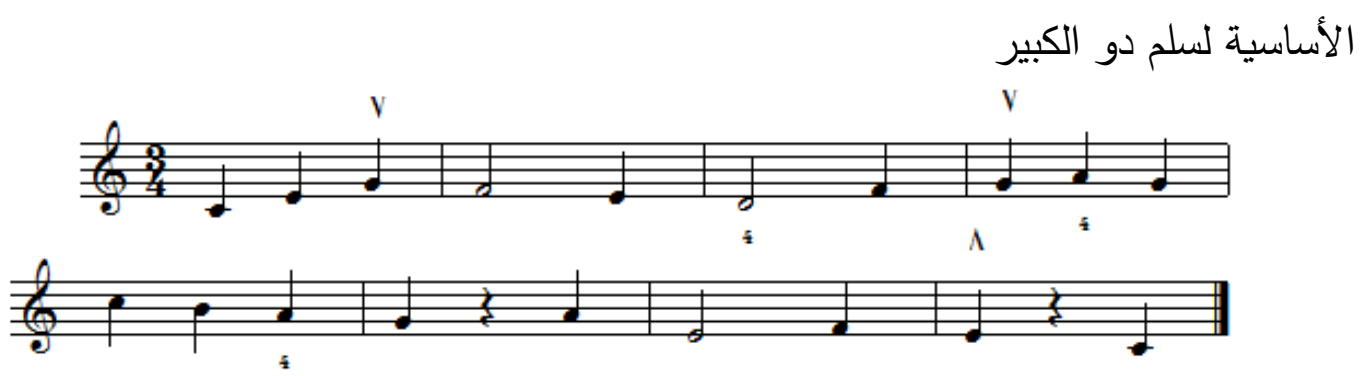

شكل رقم († ا ) يوضح تمرين مستوحي من الجزء الثاني من مقطوعة رقم (Y0) من كتاب سوزوكي THE Little Sevcik

$$
\text { أهداف التدريب : }
$$

) Legato Bowing ( التدريب على الأقواس (المنفصلة ) Detache ) والأقوس الكاملة ( whole bow - التدريب على مسافات لحنية (سص، rص، rك، عت) ويوجد مصاحبة لحنية على بعد (זص، بك ، آص، آك ) وهي بنفس العلامات الإيقاعية مما يساعد الدارس على الحفاظ على الوحدة الزمنية

- - التدريب على العزف في ميزان ( 3 ( ) -

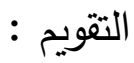
وجد الباحث أن بعض الطلاب يعزفون نغمات غير سليمة أثناء أداء سلم دو الكبير ، ولكن مع توجيه الباحث ووضع الأصابع فى الأماكن الصحيحة والمتابعة والتكرار أصبح الأداء جيداً.

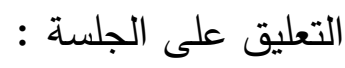
الجلسة كانت هادفة ومشوقة خاصة مع استخدام التدريس عن بعد من خلال برنامج Zoom، مع إلتزام الطلاب بالحضور • 


\section{الحلسة العاشرة}

مدة الجلسة : 0 مـ دقيقة

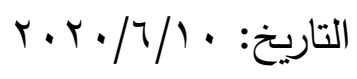

- موضوع الجلسة : التدريب علي عزف سلم صول الكبير - مقطوعة رقم (مب)

"The Little Sevcik" من كتاب "Long Long Ago"

$$
\text { rتنفيذ الجلسة : }
$$

"Long Long Ago" يستمع الطلاب الى مقطوعة رقم (ro) -

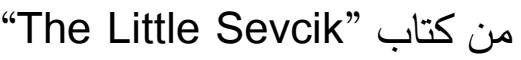
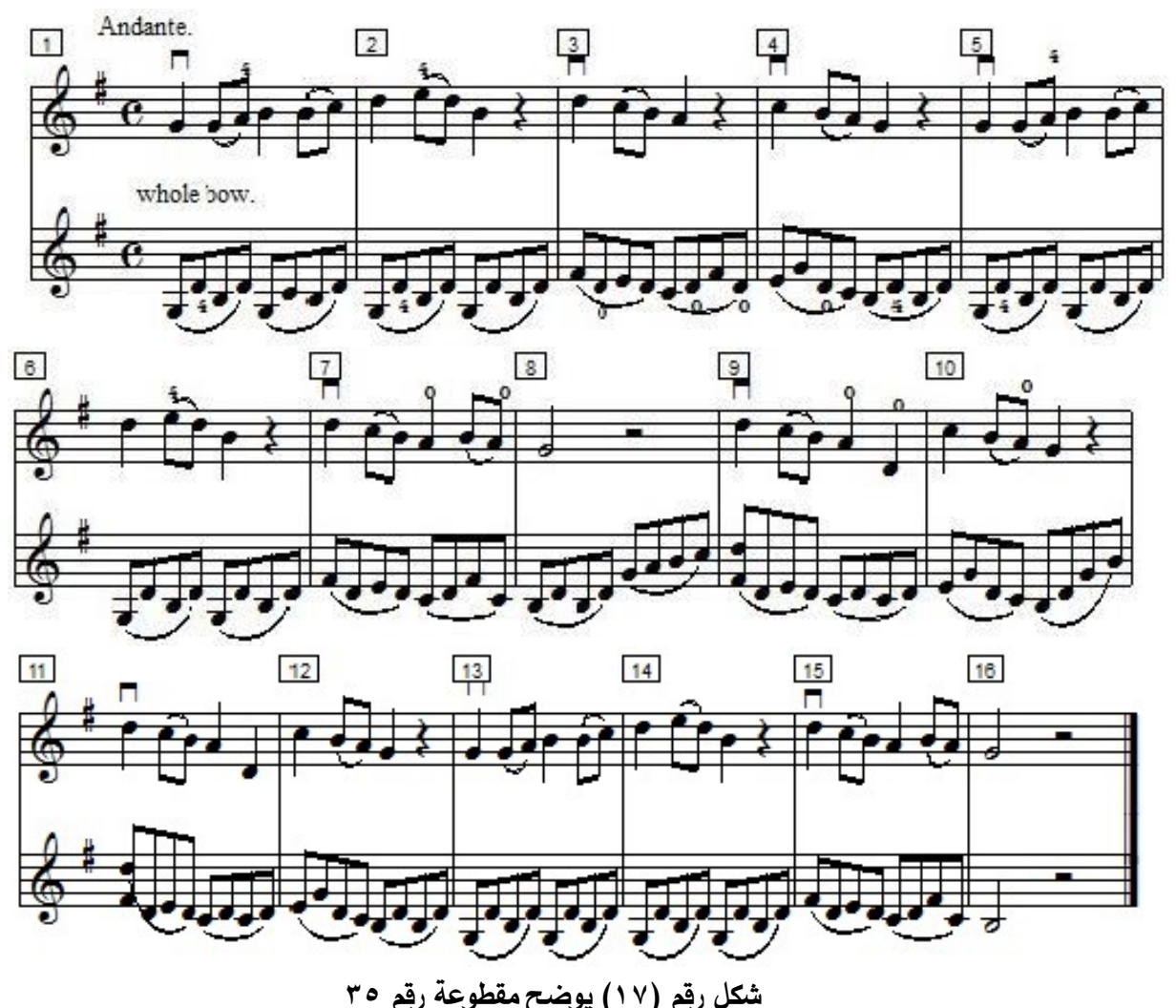

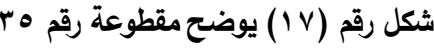


- يتم عزف سلم صول الكبير وأربيجه بالثكل التالي :
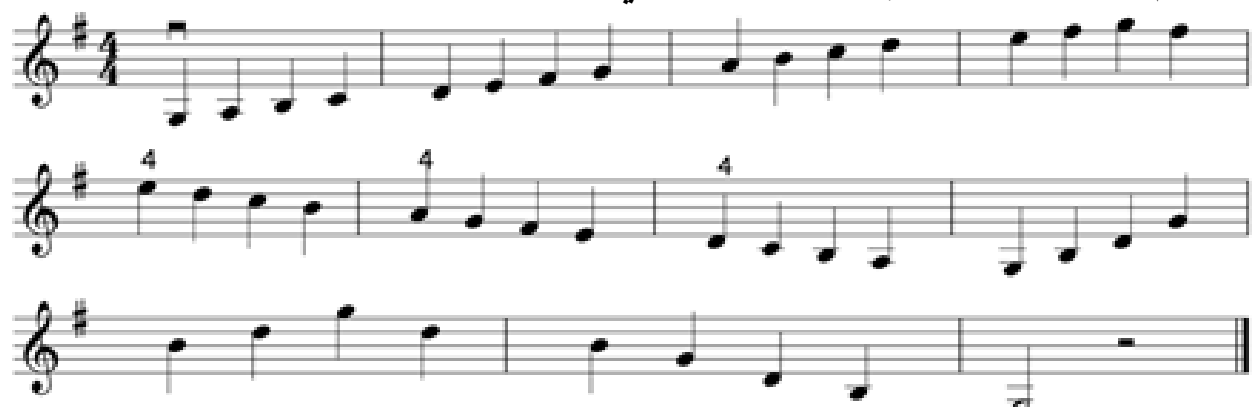

شكل رقم (1) يوضح سلم صول الكبير r اوكتاف والاربيج

شرح التمرين :

- whole bow (والأقوس الكاملة ( Legato Bowing التدريب على ( الأقواس المتصلة ) -

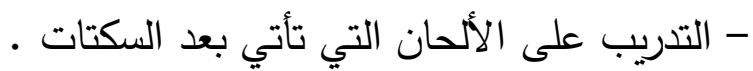

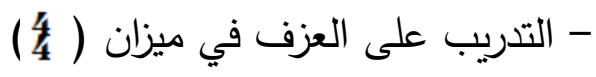
التقويم :

وجد الباحث أن بعض الطلاب يعزفون نغمات غير سليمة أثناء أداء سلم صول الكبير ، ولكن مع

توجيه الباحث ووضع الأصابع فى الأماكن الصحيحة والمتابعة والتكرار أصبح الأداء جيداً.

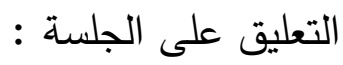

الجلسة كانت هادفة ومشوقة خاصة مع استخدام التدريس عن بعد من خلال برنامج Zoom، مع

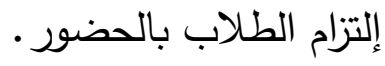

\section{عرض نتائج البحث فى ضوء فروض البحث:

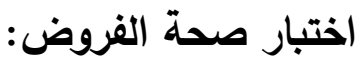

لإختبار صـــحة الاختبار القبلى بعدي والذى ينص على أنه: "يوجد فرق دال إحصــائياً بين

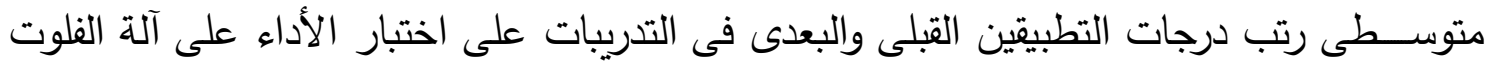

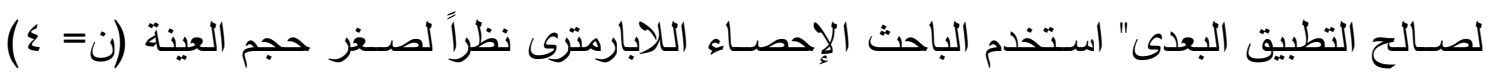

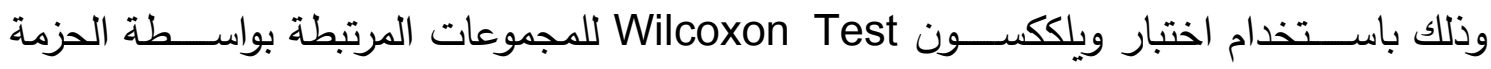

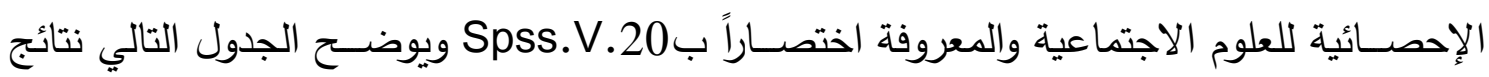

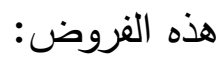

مجلة علوم وفنون الموسيقى - كلية التربية الموسيقية - المجلد الخامس والأربعوز - يوليو الr.rم 


\begin{tabular}{|c|c|c|c|c|c|c|}
\hline مستوى الدلالة & قيمة Z & مجموع الرتب & متوسط & العدد & الرتب & المتغير \\
\hline \multirow{4}{*}{$\ldots 0$} & \multirow{4}{*}{$1 . \wedge \varepsilon$} & . & • & . & السالبة & \multirow{4}{*}{ التدريب الأول } \\
\hline & & 1. & Y.० & $\varepsilon$ & الموجبة & \\
\hline & & - & - & . & المتساوية & \\
\hline & & - & - & $\varepsilon$ & المجموع & \\
\hline
\end{tabular}

يوضح نتائج اختبار ويلككسون في التدريبات على اختبار الأداء على آلة الكمان للتطبيقين التبلى والبعدى

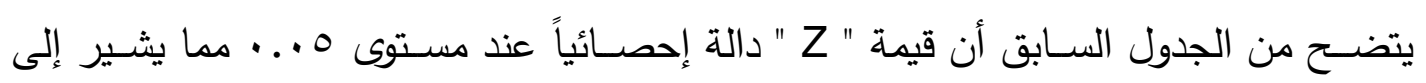

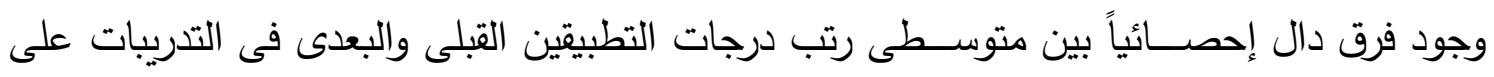

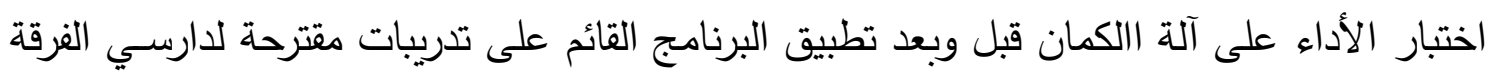
الاولي بالتدريس عن بعد لصالح التطبيق البعدى.

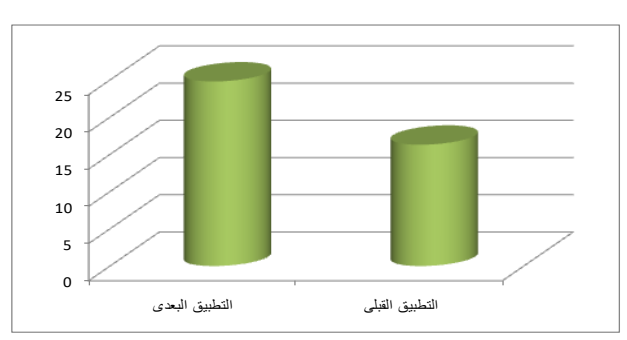

يوضح رسم بيانى لمتوسطى درجات التطبيقين القبلى والبعدى فى التدريب على اختبار الأداء على آلة الكمان نتائَج البحث:

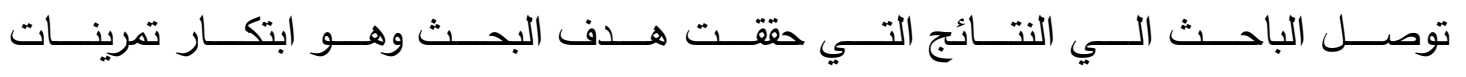

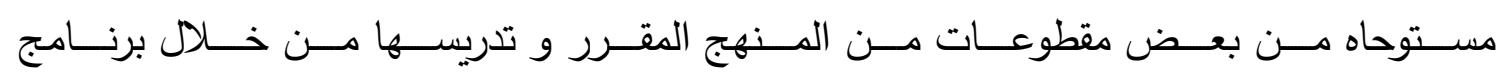

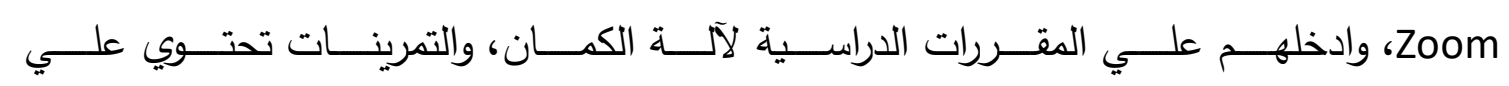
جمل لحنية وتتنيات العزف المختلفة مما يساعد علي تحسين أداء آلة الكمان. 


\section{توصيات البحث:}

1- الاهتمام بالتتوع في المصادر التعليمية لآلة الكمان وذلك باستخدام أساليب التدريب المختلفة ومهارات العزف التي تساعد الطلاب علي الارتقاء بمستوي الاداء.

r- - تدعيم دارسي آلة الكمان بأساليب التدريب المتتوعة ومهارات العزف المختلفة علي آلة الكمان.

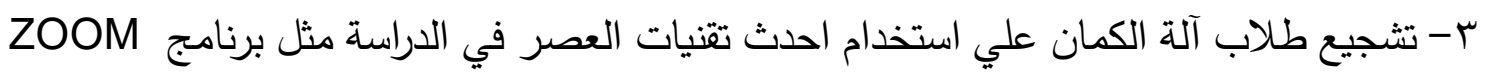
وغيره، مما يسهم في تحسين أسلوب الأداء عندهم. 


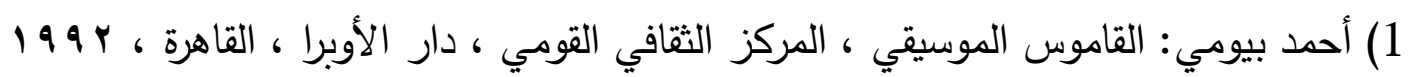

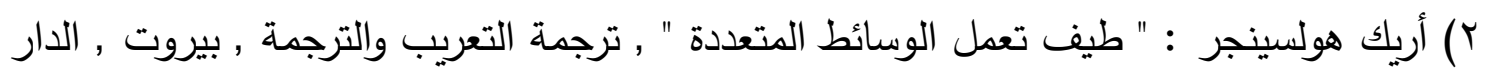

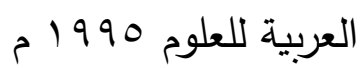
r) أحمد حسين اللقاني : " المنهج - الأسس , والمكونات , التتظيمات " , عالم الكتب , القاهرة , $.0199 \mathrm{~V}$ §) أحمد اللقاني وعلي الجمل : " معجم المصطلحات التربوية المعرفة في المناهج وطرق التدريس "

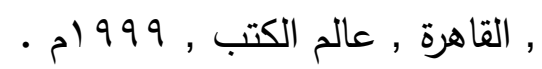

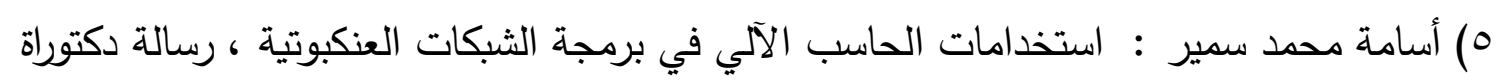
، كلية الهندسة ، جامعة القاهرة.

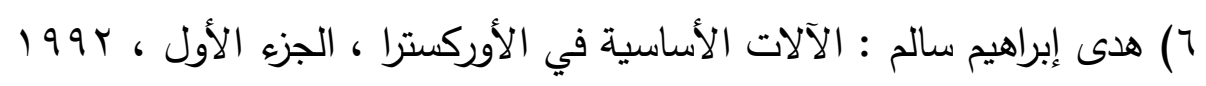

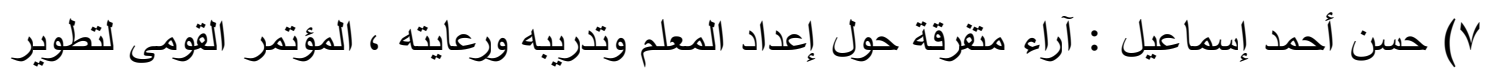

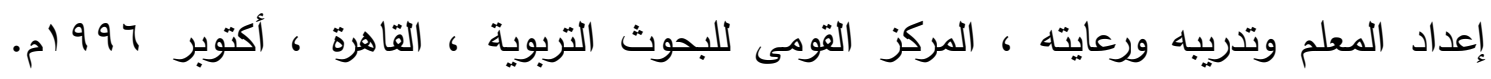

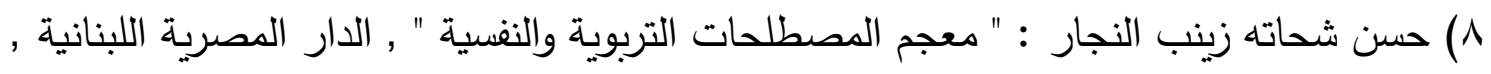
$\cdot r$

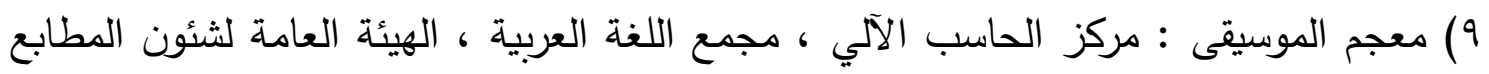

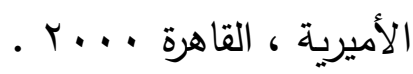
• ( ) سهير احمد محمد : رسالة دكتورة غير منسورة ، كلية التربية بالإسماعيلية (جامعة قناة السويس) 199V。

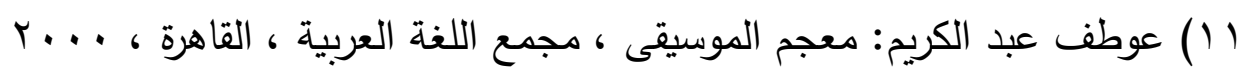

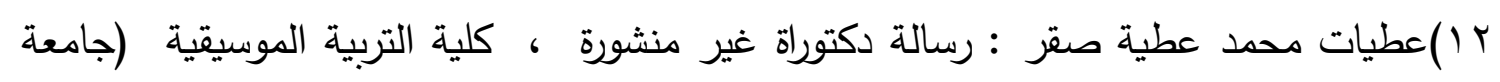

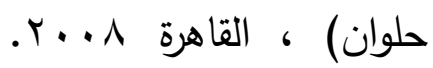

با () نيفين مسعد الدحمودي: تقنيات الفيولينة في أعمال خاتثدوريان ، رسالة ماجستير ، المعهد

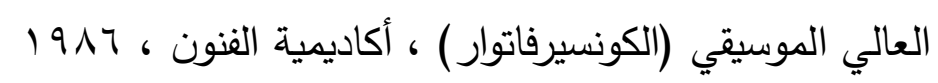

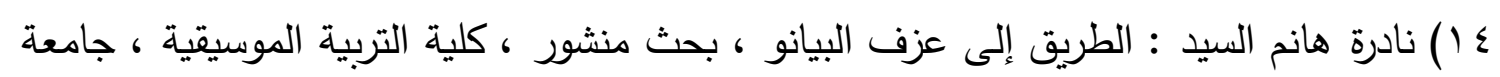

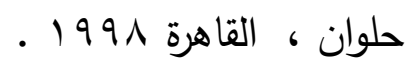


1 1) ندي بنت ناجي زرنزقي : " أثر استخدام الحاسب الألي في تتمية التفكير الإبتكاري والتحصيل

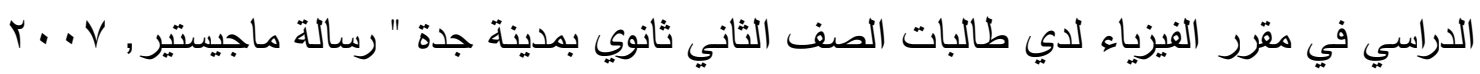

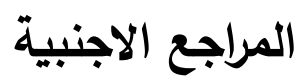

1) Carl Flash: the art of violin playing, book one, New York, 1939

2) Ivan Galamian : Principles of violin Playing and Teaching Prentice-xall. Inc. Englewood. Cliffs. N.G. , 1962.

3) I.M. Yambol sky: The Principles Of Violin Fingering, Oxford University Press, London, 1971

4) Jodi L , Longitudinal Analysis of Student Performance in a Dental Hygiene Distance Education Program, Journal of Dental Education Volume 66, No. 9,2002

5) William Pleeth - Cello - Schirmer Books ( Macmillan inc. ) - New York 1982.

6) Lepold Auer : Violin playing as I teach it, New York, Dover Publication, Inc1980

7) Ruth Midgley \& others , Musical instruments of the world, new York, oxford, 1967

8) Silver Mirian : edd, New Lark University, 1982.

9) Tsuneaki Miyoshi: Design, typewriting and printing by the printer University of Centerburg, 1992. 


\section{ملخص البحث}

برنامج مقترح لتدريس آلة الكمان عن بعد للطالب المتخصص من خلال

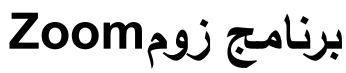

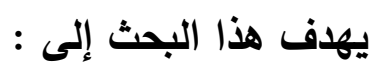

تصميم برنامج مقترح لدراسة آلة الكمان عبر الأنترنت باستخدام برنامج زوم Zoom للطالب البان

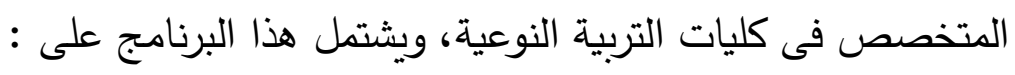
( ) تقنيات الأداء لحركة القوس باليد اليمنى صعوداً وهبوطاً.

r السلالم المناسبة للمرحلة الدراسية.

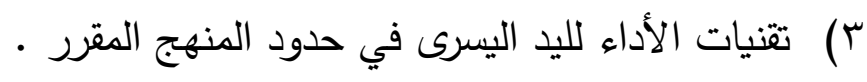

$$
\begin{aligned}
& \text { وينقسم البحث الى جزئين:- } \\
& \text { اولاً: الاطار النظرى ويشمل : } \\
& \text { - دراسات سابقة. }
\end{aligned}
$$

- - إستخدامات برنامج زوم Zoom بواسطة الحاسب الآلي او التليفون المحمول.

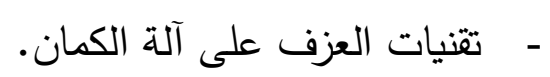

ثانيا : الإطار التطبيقي :ويضم الإجراءات والخطوات التى تم إتباعها لتحقيق أهداف البحث. 


\section{Research Summary}

A Proposed Program for Teaching the Violin from a Distance to the Specialized Student Through the Zoom Program

This Research Aims to:

Designing a Proposed Program to Study the Violin via the Internet using the Zoom

Program for Students Specialized in Faculties of Specific Education, and this Program includes:

1- Performance Techniques for Up and Down Right-handed Bow Movement.

2- Stairs Appropriate to the School Stage.

3- Performance Techniques for the left hand within the Prescribed Curriculum.

The Research is Divided Into Two Parts:

First: The theoretical framework and includes:

- previous studies Computer uses and Mobile Through Zoom Platform

- Techniques of playing the violin

Second: The application framework: It includes the procedures and steps that were followed to achieve the research objectives. 